\section{Market Anticipations of Monetary Policy Actions}

\author{
William Poole, Robert H. Rasche, and \\ Daniel L. Thornton
}

T he purpose of this paper is to investigate the extent to which market participants anticipate Federal Reserve policy actions. The topic is central to macroeconomics. Since the early 1970s theorists have emphasized that a complete model of the economy requires a full specification of the behavior of policymakers. Otherwise, there is no way to model the expectations upon which private agents base their decisions.

The recent trend in monetary policy has been toward greater transparency, accountability, and credibility. This trend is largely explained by two ideas. First, the economics profession has accepted the proposition that monetary policy is the fundamental determinant of inflation in the long run. ${ }^{1}$ Second, central bank credibility and clear market expectations about monetary policy are critical to policy success. ${ }^{2}$

The key theoretical development in this context was the application of rational expectations to macroeconomics and the statement of the famous Lucas critique. Lucas (1976) argued that the economy and policymakers are interdependent. Specifically, the public forms expectations of the dynamic feedback rule that policymakers follow to implement policy. This line of argument led naturally and immediately to the distinction between expected and surprise policy actions and a number of papers exploring their different effects on the economy. ${ }^{3}$ For example, the more transparent the central bank, the less likely that it will be able to institute a surprise inflation to temporarily raise output growth.

Our purpose is not to add to the extensive theoretical literature, but instead to document in considerable detail the extent to which U.S. monetary policy has become increasingly open and trans-

William Poole is the president, Robert $\mathrm{H}$. Rasche is a senior vice president and director of research, and Daniel $\mathrm{L}$. Thornton is a vice president and economic advisor at the Federal Reserve Bank of St. Louis. Kathy Cosgrove and Charles Hokayem provided research assistance.

(C) 2002, The Federal Reserve Bank of St. Louis. parent. The trend toward greater transparency has been especially evident in recent years. ${ }^{4}$ In 1994 , the FOMC began the practice of announcing policy actions immediately upon making them, and in 1995 the practice was formally adopted. ${ }^{5}$ Since August 1997 the FOMC has included a numeric value of the "intended federal funds rate" in each directive. Since May 1999 a press statement has been released at the conclusion of every meeting. These press statements initially included a numeric value for the "intended federal funds rate" and a statement of the "policy bias."

In February 2000 the FOMC replaced the "policy bias" in the Directive that had been used since February 1983 with a statement of the "balance of risks." ${ }^{\prime}$ In this statement the FOMC indicates its beliefs about how the risks of heightened inflation pressure and economic weakness are balanced over the foreseeable future. The new language was not intended to indicate the likely direction or timing of future policy moves.

These moves toward greater openness and transparency should have increased the ability of markets to anticipate policy actions. Poole and Rasche (2000) and Kuttner (2001) used data from the federal funds futures market to estimate the extent to which the market has anticipated the Fed's actions. While their methodologies differ slightly,

1 There is a continuing debate, however, about exactly how central banks control the long-run inflation rate and the relative importance of money. For further discussion, see McCallum (2001).

2 In the final analysis, credibility is earned-central banks will be known by their actions, not by their words. The Swiss National Bank and the Bundesbank had considerable credibility because they kept the inflation rate low. See Meyer (2001) for a discussion of the need to earn credibility.

3 A number of arguments have been advanced for why only surprise policy actions matter. Recently, Woodford (2001) presented arguments against several of these propositions. Indeed, he shows that in models with forward-looking expectations, what matters is the market's expectation of future policy. The remaining argument against expected policy having real effects occurs if prices adjust very rapidly to expected policy actions. In such an environment, policymakers would be unable to change the stock of real money and, consequently, unable to affect any real variable. For a recent attempt to differentiate empirically between the effects of expected and unexpected policy actions, see Hoover and Jorda (2001).

4 In its landmark Freedom of Information Act case (Merrill vs. FOMC) that was argued before the U. S. Supreme Court in 1976, the Fed vigorously defended the need for secrecy. See Goodfriend (1986) for a discussion of the Merrill case and the Fed's arguments.

5 For a detailed history of the Fed's disclosure practice, see Rasche (2001).

6 See Thornton and Wheelock (2000) for a detailed analysis of the policy bias statement. 
both looked at the reaction of the federal funds futures rate on days when the Fed changed the funds rate target; in this way, they estimated the extent to which the market was surprised by Fed actions. The expected target change is obtained by subtracting this estimate from the actual target change. These measures were then used to estimate the response of market rates to unexpected changes in policy. Both analyses find that Treasury rates responded significantly to unexpected target changes, but not to expected target changes.

This paper extends this literature in several important directions. First, because this methodology requires that market participants know that the Fed has changed the funds rate target, we perform the analysis separately over the two periods: pre-1994 and post-1993. (Pre-1994 refers to the period before the February 4, 1994, FOMC meeting; post1993 refers to the period after that meeting.) As of February 4, 1994, there is no doubt that the market has been aware each time the target was changed because each change has been announced. Before 1994 the market's knowledge of Fed actions cannot be taken for granted. Consequently, we undertake a detailed analysis of what the market knew about Fed policy actions before 1994 to determine instances when market participants were and were not aware that the target had changed.

Second, we show that the Poole/Rasche and Kuttner methodology eliminates part, but not all, of the measurement error associated with identifying unexpected changes in the funds rate target. Failure to account for the remaining source of measurement error results in a downward bias in the estimate of the response of the Treasury rates to unexpected target changes. We implement an errorsin-variables estimator to correct for this bias.

Third, we attempt to identify the extent to which market participants were surprised by the Fed's inaction. That is, we identify dates when the market expected the Fed to act but no action was taken. This is particularly relevant for the post 1993 period. Given the FOMC's practice since 1993 of changing the target primarily at regularly scheduled meetings, it is reasonable to assume that there may have been instances when the market was expecting an action that the FOMC did not take. The absence of action may have prompted market participants to revise their expectation for the future funds rate.

Fourth, we investigate how far in advance the market appeared to correctly anticipate a policy action. The Poole/Rasche and Kuttner methodology indicates only whether the market anticipated the Fed's action at the time the action was taken; it does not provide information about how far in advance the market expected the action. This measurement required a detailed analysis of what the market expected and the behavior of longer-term federal funds futures rates.

Finally, we provide additional evidence that the recent trend toward greater transparency has significantly increased market participants' ability to anticipate Fed actions.

\section{IDENTIFYING UNEXPECTED MONETARY POLICY ACTIONS}

One problem in estimating the response of the economy to exogenous policy actions of the Fed has been that it has been difficult to isolate a variable that measures such actions. The search for a single measure of exogenous Fed policy actions has been hampered by the fact that the Fed has changed its emphasis in conducting monetary policy over the years.

The practice of changing operating procedures, and in some instances changing policy objectives, combined with the lack of transparency about either the Fed's objectives or its operating procedure makes it very difficult to isolate one variable that reflects Fed policy actions. It is hardly surprising that a number of variables - growth rates of monetary and reserve aggregates, changes in the discount rate, and short-term interest rates, particularly the overnight federal funds rate- have been used as measures of Fed policy actions.

Knowing the Fed's policy instrument is an important element for assessing the effect of monetary policy actions, but it is not the only element. If markets are efficient, anticipated policy actions are already reflected in economic variables - markets respond only to unexpected policy actions. To identify the effect of policy actions on the economy, the observed policy instrument must be partitioned into its expected and unexpected components. Failure to distinguish between expected and unexpected policy actions gives rise to a measurement problem, which biases downward the estimated response of economic variables to a change in the policy instrument. To correctly assess the impact of policy actions, then, the policy instrument must be known, observed, and partitioned into its expected and unexpected components.

There is little difficulty in identifying policy 
actions since the late 1980s. For one thing, the Fed has explicitly targeted the federal funds rate during this period and there is evidence that the market was aware that the Fed targeted the funds rate as early as 1989. In addition, in October 1988 the Chicago Board of Trade began trading federal funds futures contracts. A federal funds futures contract is a bet on the average effective federal funds rate for the month in which the contract matures. Consequently, the federal funds futures rate reflects the market's expectation for the average level of the federal funds rate for that month. In this environment, the federal funds futures rate is a nearly ideal measure of the market's expectation of Fed policy. To illustrate, let $f f f_{t}^{h}$ denote the rate on the $h$-month federal funds futures contract on day $t$. Note that

$$
f f f_{t}^{h} \equiv(1 / m) \sum_{i=1}^{m} E_{t} f f_{i}^{h},
$$

where $f f_{i}^{h}$ denotes the federal funds rate on day $i$ of the $h$ th month, $E_{t}$ denotes the expectation on day $t$, and $m$ denotes the number of days in the month.

Now assume that the Fed is targeting the federal funds rate and that the funds rate stays very close to the target, i.e.,

$$
f f_{t}=f f_{t}^{*}+\eta_{t},
$$

where $f f_{t}^{*}$ denotes the Fed's target for the federal funds rate on day $t$ and $\eta_{t}$ denotes a mean zero, but not necessarily i.i.d., random variable. ${ }^{7}$ Substituting (2) into (1) yields

$$
f f f_{t}^{h} \equiv(1 / m) \sum_{i=1}^{m} E_{t} f f_{i}^{* h} .8
$$

On day $t$, the change in the $h$-month federal funds futures rate would be

$$
\Delta f f f_{t}^{h} \equiv(1 / m) \sum_{i=1}^{m}\left(E_{t} f f_{i}^{* h}-E_{t-1} f f_{i}^{* h}\right) .
$$

Suppose that on day $t$ there is a change in the intended funds rate that is expected to persist for $h$ months or longer. If market participants correctly anticipate both the timing and the magnitude of the Fed's action, the $h$-month-ahead federal funds futures rate would not respond to the action, i.e., $\Delta f f f_{t}^{h}=0$. The change in the $h$-month-ahead federal funds futures rate on days when the market knows that the Fed has changed its funds rate target is a measure of the unexpected change in the target, so long as the new target is expected to persist for the term of the futures contract. The expected target change can be calculated by subtracting this number from the actual target change.

Poole/Rasche and Kuttner use this procedure to identify unexpected policy actions. Poole and Rasche use the change in the 1-month federal funds futures rate on the day the target was changed. On the first day of the month $f f f_{t-1}^{1}$ is replaced by the futures rate on the 2-month contract for the last day of the previous month.

In contrast, Kuttner estimates the unexpected target change using the current month's futures rate contract. Specifically, Kuttner's estimate of the unexpected target change is

$$
\Delta f f_{t}^{* u} \equiv \frac{m}{m-t}\left(f f f_{t}^{0}-f f f_{t-1}^{0}\right),
$$

where $f f f_{t}^{0}$ is the value of the current month's federal funds futures rate on the $t$ th day of the month and $m$ is the number of days in the month. On the first day of the month, $f f f_{t-1}^{0}$ is replaced by the futures rate on the 1-month contract on the last day of the previous month. On the last three days of the month, Kuttner uses the Poole/Rasche measure of the unexpected target change.

\section{Knowledge of Fed Actions}

These measures presume that market participants are aware of the target change. If the market participants are unaware that the target has changed, expectations for the funds rate would not necessarily reflect expectations for the Fed's policy instrument. Even if market participants were aware that the Fed had taken some policy action, evidenced, for example, by a change in the discount rate, the change in the federal funds futures rate would not necessarily reflect the "unexpected change in the funds rate target."

Likewise, if market participants do not know that the target has changed on a particular day, that day's change in the federal funds futures rate could not measure the unexpected change in the funds rate target. Indeed, on such days the change in the futures rate would normally be relatively small, which might be interpreted as the market having expected the target change. In truth, however, market participants would be simply unaware that the target had changed.

After 1994, knowledge of FOMC actions is not an issue. As previously stated, at its February 4, 1994,

7 There is some well-documented persistence in deviations of the funds rate from the funds rate target. For example, see Taylor (2001)

8 This and subsequent analyses ignore the possibility of a small premium in the futures market, documented by Robertson and Thornton (1997), because any such premium is so small that its existence would have a negligible impact. 
meeting, the FOMC began the practice of announcing target changes immediately. ${ }^{9}$ Knowledge of target changes before 1994, when target changes were not announced, is problematic. The process of knowing when the target was changed was further complicated by the fact that during this period most target changes were made between, rather than at, FOMC meetings. Furthermore, until late 1989 (when the Fed appears to have adopted the practice of changing the target only in multiples of 25 basis points), target changes of various amounts smaller than 25 basis points were common.

\section{THE MARKET REACTION TO UNEXPECTED TARGET CHANGES - POST-1993}

In this section we estimate the response of market rates to unanticipated changes in the funds rate target. We begin by analyzing the post- 1993 period. The policy action on February 4, 1994, is excluded from our analysis because this is the first time that the FOMC announced its decision. Since there was no information prior to the conclusion of that meeting to indicate that such an announcement would be forthcoming, market reaction was conditioned on less information than at subsequent meetings.

To estimate the response of various Treasury rates to changes in the funds rate target, Poolel Rasche and Kuttner estimated the equation

$$
\Delta i_{t}=\alpha+\beta_{1} \Delta f f_{t}^{*} e+\beta_{2} \Delta f f_{t}^{*} u+\varepsilon_{t},
$$

where $\Delta i_{t}$ denotes the change in the selected Treasury rate and $\Delta f f_{t}^{*_{e}}$ denotes the expected change in the funds rate target, i.e., $\Delta f f_{t}{ }^{*}=\Delta f f_{t}{ }^{*}-\Delta f f_{t}{ }^{*}{ }$.

Ordinary least-squares (OLS) estimates of $\beta_{1}$ and $\beta_{2}$ are biased because the measures of the unexpected target change suffer from measurement error. The measurement error arises because each day markets process information that comes in various forms. While special attention is paid to headline news - reports of major government statistics, announcements of funds rate target changes, etc.market participants process information from a variety of other sources that are less easily identified. Hence, federal funds futures rates change even on days when there is no headline news or a target change. Such ambient news is included in the Poole/ Rasche and Kuttner measures of the unexpected change in the funds rate target.

We adjust for the errors-in-variable bias using a classic econometric approach. It is convenient to rewrite (6) so there is only one variable that is measured with error:

$$
\Delta i_{t}=\alpha+\beta_{1}\left(\Delta f f_{t}^{*}-\Delta f f_{t}^{*} u\right)+\beta_{2} \Delta f f_{t}^{*} u+\varepsilon_{t},
$$

which simplifies to

$$
\Delta i_{t}=\alpha+\beta_{1} \Delta f f_{t}^{*}+\left(\beta_{2}-\beta_{1}\right) \Delta f f_{t}^{* u}+\varepsilon_{t} .
$$

\section{Classic Errors-in-Variables Model}

Errors-in-variables bias arises when one of the variables is measured with error. To illustrate the problem and the corresponding errors-in-variables estimation, assume that

$$
\Delta f f_{t}^{*} u m=\Delta f f_{t}^{*} u+u_{t},
$$

where $\Delta f f_{t}^{*} u m$ is an estimate of the true unexpected change in the funds rate target and $u_{t}$ is a random measurement error that is uncorrelated with $\Delta f f_{t}^{*_{u} u}$. Substituting (9) into (8) yields

$$
\begin{aligned}
\Delta i_{t} & =\alpha+\beta_{1} \Delta f f_{t}^{*}+\left(\beta_{2}-\beta_{1}\right) \Delta f f_{t}^{*} u m-u_{t}+\varepsilon_{t} \\
& =\alpha+\beta_{1} \Delta f f_{t}^{*}+\left(\beta_{2}-\beta_{1}\right) \Delta f f_{t}^{*} u m+\varpi_{t} .
\end{aligned}
$$

It is clear from (10) that $\Delta f f_{t}^{*} u m$ is negatively correlated with $\varpi_{t}$, which will bias the estimate of $\left(\beta_{2}-\beta_{1}\right)$ down. The classic errors-in-variables estimator makes use of the assumptions that $E u_{t}=E \varepsilon_{t}=0$ and $E u_{t} \varepsilon_{t}=0$. Under these assumptions, the covariance between $\left(\beta_{2}-\beta_{1}\right) \Delta f f_{t}^{*}$ um and $\varpi_{t}$ is $-\left(\beta_{2}-\beta_{1}\right) \sigma_{u}^{2}$, where $\sigma_{u}^{2}$ is the variance of the measurement error. ${ }^{10}$

\section{Identifying Ambient Variation in the Futures Rate}

The application of the classic errors-in-variables estimation technique requires a measure of the variance of the shock associated with the ambient news. We accomplish this by identifying all of the policy events since 1994. A policy event is either a meeting of the FOMC or an intermeeting target change. During this period all but four of the target changes occurred at regularly scheduled FOMC meetings. There were 62 such events from March 1994 through May 2001. We then read the front page and the Credit Markets column of the Wall Street Journal (WSJ) at least two days before each of these events to infer what the market anticipated would happen on "event days."

\footnotetext{
9 The FOMC formally adopted this practice as a procedure at its JanuaryFebruary 1995 meeting.

${ }^{10}$ For more details, see Johnston (1963, pp. 168-70).
} 
On meeting days when the target was not changed, we concluded that the market anticipated that no action would be taken if the commentary suggested that market analysts overwhelmingly believed that no action would be taken. We inferred that the market anticipated no action when the WSJ reported there was a "consensus" or "unanimity" among market analysts.

When the funds rate target was changed, we required market analysts to correctly anticipate the magnitude of the target change. In many cases the WSJ reported the results of a survey. In these instances, we inferred that the market correctly anticipated the FOMC's action if more than threefourths of the survey respondents correctly predicted the action.

This procedure resulted in the contingency table shown in Table 1. The dates for each of these groups and the corresponding Poole/Rasche and Kuttner shock measures are presented in Table $2 .{ }^{11}$ Of the 62 events since March 1994, we conclude the market fully anticipated 44. For most of these events the FOMC did not change the funds rate. On only four occasions when there was no target change did we conclude the market was surprised. The target was changed 24 times during this period. We conclude market participants were surprised on 14 of these occasions.

Our classification using the WSJ is generally supported by the shock measure. There are only two occasions when the Poole/Rasche shock measure was larger than 5 basis points when our reading of the WSJ indicated that the market expected the FOMC's action. On both of these occasions, the target was changed. Moreover, when our reading of the WSJ indicated that the market was surprised by the action, the Poole/Rasche shock measure is larger than 5 basis points on all but three occasions. Market participants appear to have been surprised by all four of the intermeeting target changes. Indeed, three of the four largest shocks by either measure occurred on these days. This suggests that, while the market may be able to anticipate the direction and size of the next target change, predicting the timing of an action is difficult unless the FOMC follows a rule, such as only adjusting the funds rate target at regularly scheduled meetings.

\section{The Results}

The variance of the observed change in the 1month federal funds futures rate for the 44 events in the second row of Table 1 is our estimate of $\sigma_{u}^{2}$, the variance of the measurement error. OLS estimates

\section{Table 1}

Contingency Table of Anticipated and Unanticipated Events Obtained from the Wall Street Journal

\begin{tabular}{lccc} 
& $\begin{array}{c}\text { No target } \\
\text { change }\end{array}$ & $\begin{array}{c}\text { Target } \\
\text { change }\end{array}$ & Total \\
\hline Surprise & 4 & 14 & 18 \\
No surprise & 34 & 10 & 44 \\
Total & 38 & 24 & 62 \\
\hline
\end{tabular}

and estimates obtained using a classic errors-invariables estimation technique (EV) are presented in Tables 3 and 4 for the post- 1993 period using the Poole/Rasche and Kuttner shocks, respectively. Not surprisingly, the OLS estimates suffer from errorsin-variables bias. In all cases, EV estimates of $\beta_{2}$ are larger than the corresponding OLS estimates. The response of these rates to target shocks is larger with the Poole/Rasche measure than with the Kuttner measure, but the differences are generally small. Figure 1, which shows the two measures of target shocks, reveals that there is close correspondence between these measures. ${ }^{12}$ Hence, it is hardly surprising that these measures yield very similar results. As a result, only the Poole/Rasche shock will be presented in the remainder of the paper.

\section{Do Markets Respond to Expected Target Changes?}

One unexpected result is the finding that the 3-month rate responds significantly to actual target changes, suggesting that the market responds to expected changes. The estimated coefficient on the target change in the regression for the 3-month rate is statistically significant at the 5 percent level. This result is at odds with the efficient markets hypothesis and with Poole/Rasche and Kuttner, who found that markets did not respond to anticipated target changes. It is also at odds with our findings (presented in the next section) for the pre-1994 period.

Kuttner (2001) reports a similar result when he used monthly average data. Specifically, he found that both the 3-and 6-month T-bill rates responded significantly to his measure of the surprise target

\footnotetext{
11 As Kuttner (2001) has noted, the change on October 15, 1998, was announced at 3:15 p.m. Eastern time, after the markets closed. Consequently, for the purpose of the empirical analysis, this change is dated as October 16

12 The simple correlation between these measures is 0.98 .
} 


\section{Table 2}

Dates and Poole/Rasche and Kuttner Shock Measures Corresponding to Table 1

\begin{tabular}{|c|c|c|c|}
\hline Date & Poole/Rasche & Kuttner & $\begin{array}{c}\text { Figure reference } \\
\text { number }\end{array}$ \\
\hline \multicolumn{4}{|c|}{ Surprise/no target change } \\
\hline 9/27/94 & -0.08 & -0.20 & Figure 7 \\
\hline $12 / 20 / 94$ & -0.11 & -0.17 & Figure A1-A \\
\hline 9/24/96 & -0.13 & -0.12 & Figure 6 \\
\hline $5 / 20 / 97$ & -0.09 & -0.11 & Figure A1-B \\
\hline \multicolumn{4}{|c|}{ Surprise/target change } \\
\hline $3 / 22 / 94$ & -0.04 & -0.03 & Figure 4 \\
\hline $4 / 18 / 94^{*}$ & 0.10 & 0.10 & Figure 2 \\
\hline $5 / 17 / 94$ & 0.05 & 0.13 & Figure 3 \\
\hline 8/16/94 & 0.10 & 0.14 & Figure A2-A \\
\hline 11/15/94 & 0.09 & 0.14 & Figure A2-B \\
\hline $7 / 06 / 95$ & -0.07 & -0.01 & Figure A2-C \\
\hline $12 / 19 / 95$ & -0.11 & -0.10 & Figure A2-D \\
\hline $1 / 31 / 96$ & -0.07 & -0.07 & Figure A2-E \\
\hline $10 / 16 / 98^{*}$ & -0.20 & -0.26 & Figure A2-F \\
\hline 11/17/98 & -0.06 & -0.06 & Figure A2-G \\
\hline 11/16/99 & 0.08 & 0.09 & Figure A2-H \\
\hline $1 / 03 / 01^{*}$ & -0.29 & -0.38 & Figure A2-I \\
\hline $3 / 20 / 01$ & 0.03 & 0.06 & Figure 5 \\
\hline $4 / 18 / 01^{*}$ & -0.42 & -0.43 & Figure A2-J \\
\hline \multicolumn{4}{|c|}{ No surprise/no target change } \\
\hline $7 / 06 / 94$ & -0.02 & -0.05 & NA \\
\hline 3/28/95 & 0.00 & 0.10 & NA \\
\hline $5 / 23 / 95$ & 0.01 & 0.00 & NA \\
\hline 8/22/95 & 0.02 & 0.00 & NA \\
\hline 9/26/95 & 0.04 & 0.00 & NA \\
\hline 11/15/95 & 0.01 & 0.06 & NA \\
\hline $3 / 26 / 96$ & 0.01 & -0.03 & NA \\
\hline $5 / 21 / 96$ & 0.01 & 0.00 & NA \\
\hline $7 / 03 / 96$ & -0.05 & -0.05 & NA \\
\hline 8/20/96 & -0.01 & -0.04 & NA \\
\hline $11 / 13 / 96$ & 0.01 & 0.00 & NA \\
\hline $12 / 17 / 96$ & 0.00 & 0.10 & $\mathrm{NA}$ \\
\hline
\end{tabular}

\begin{tabular}{|c|c|c|c|}
\hline Date & Poole/Rasche & Kuttner & $\begin{array}{c}\text { Figure reference } \\
\text { number }\end{array}$ \\
\hline \multicolumn{4}{|c|}{ No surprise/no target change cont'd } \\
\hline $2 / 05 / 97$ & -0.02 & -0.03 & NA \\
\hline $7 / 02 / 97$ & -0.01 & -0.02 & NA \\
\hline 8/19/97 & 0.01 & -0.01 & NA \\
\hline 9/30/97 & 0.00 & 0.00 & NA \\
\hline $11 / 12 / 97$ & -0.02 & -0.04 & NA \\
\hline $12 / 16 / 97$ & -0.01 & -0.01 & NA \\
\hline 2/04/98 & 0.01 & 0.00 & NA \\
\hline 3/31/98 & 0.00 & 0.00 & NA \\
\hline $5 / 19 / 98$ & -0.02 & -0.03 & NA \\
\hline 7/01/98 & -0.01 & -0.01 & NA \\
\hline 8/19/98 & 0.00 & 0.00 & NA \\
\hline $12 / 22 / 98$ & 0.00 & 0.00 & NA \\
\hline 2/03/99 & -0.01 & 0.00 & NA \\
\hline 3/30/99 & 0.00 & 0.00 & NA \\
\hline $5 / 18 / 99$ & -0.01 & -0.02 & NA \\
\hline $10 / 05 / 99$ & 0.00 & -0.04 & NA \\
\hline $12 / 21 / 99$ & 0.00 & 0.03 & NA \\
\hline 6/28/00 & -0.02 & -0.02 & NA \\
\hline 8/22/00 & 0.00 & 0.00 & NA \\
\hline $10 / 03 / 00$ & 0.00 & 0.00 & NA \\
\hline $11 / 15 / 00$ & 0.00 & 0.00 & NA \\
\hline $12 / 19 / 00$ & 0.05 & 0.05 & NA \\
\hline
\end{tabular}

No surprise/target change

\begin{tabular}{lrrl}
\hline $2 / 01 / 95$ & 0.02 & 0.05 & Figure A3-A \\
$3 / 25 / 97$ & 0.04 & 0.03 & Figure A3-B \\
$9 / 29 / 98$ & 0.06 & 0.06 & Figure A3-C \\
$6 / 30 / 99$ & -0.04 & -0.04 & Figure 9 \\
$8 / 24 / 99$ & 0.03 & 0.02 & Figure 10 \\
$2 / 02 / 00$ & -0.04 & -0.05 & Figure A3-D \\
$3 / 21 / 00$ & -0.01 & -0.03 & Figure 8 \\
$5 / 16 / 00$ & 0.04 & 0.05 & Figure A3-E \\
$1 / 31 / 01$ & 0.00 & 0.00 & Figure A3-F \\
5/15/01 & -0.07 & -0.08 & Figure A3-G \\
NOTE: * Indicates an intermeeting target change.
\end{tabular}




\section{Table 3}

OLS and EV Estimates of the Response of Treasury Rates to Target Surprises Using the Poole/Rasche Measure (Post-1993)

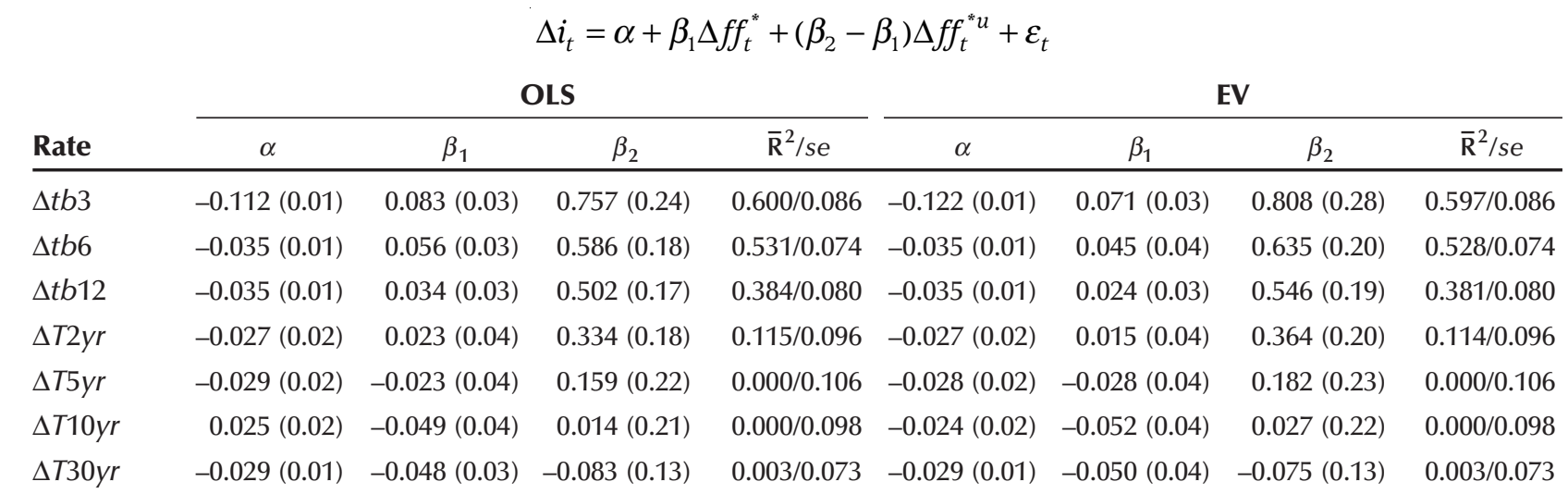

NOTE: Estimated standard errors are in parentheses.

\section{Table 4}

OLS and EV Estimates of the Response of Treasury Rates to Target Surprises Using the Kuttner Measure (Post-1993)

\begin{tabular}{|c|c|c|c|c|c|c|c|c|}
\hline \multirow[b]{2}{*}{ Rate } & \multicolumn{4}{|c|}{$\Delta i_{t}=\alpha+\beta_{1} \Delta f f_{t}^{*}+\left(\beta_{2}-\right.$} & \multicolumn{4}{|l|}{$\left.\beta_{1}\right) \Delta f f_{t}^{* u}+\varepsilon_{t}$} \\
\hline & $\alpha$ & $\beta_{1}$ & $\beta_{2}$ & $\overline{\mathrm{R}}^{2} / \mathrm{se}$ & $\alpha$ & $\beta_{1}$ & $\beta_{2}$ & $\overline{\mathrm{R}}^{2} / \mathrm{se}$ \\
\hline$\Delta t b 3$ & $-0.017(0.01)$ & $0.077(0.03)$ & $0.662(0.20)$ & $0.607 / 0.085$ & $-0.018(0.01)$ & $0.065(0.04)$ & $0.706(0.23)$ & $0.604 / 0.085$ \\
\hline$\Delta t b 6$ & $-0.040(0.01)$ & $0.059(0.04)$ & $0.489(0.15)$ & $0.506 / 0.076$ & $-0.040(0.01)$ & $0.048(0.04)$ & $0.528(0.17)$ & $0.502 / 0.076$ \\
\hline$\Delta t b 12$ & $-0.041(0.01)$ & $0.044(0.03)$ & $0.392(0.16)$ & $0.332 / 0.083$ & $-0.041(0.02)$ & $0.034(0.04)$ & $0.426(0.17)$ & $0.329 / 0.084$ \\
\hline$\Delta T 2 y r$ & $-0.034(0.02)$ & $0.046(0.04)$ & $0.204(0.17)$ & $0.053 / 0.010$ & $-0.034(0.02)$ & $0.041(0.05)$ & $0.224(0.19)$ & $0.052 / 0.100$ \\
\hline$\Delta T 5 y r$ & $-0.035(0.02)$ & $0.008(0.04)$ & $0.027(0.21)$ & $0.000 / 0.108$ & $-0.035(0.02)$ & $0.005(0.04)$ & $0.038(0.23)$ & $0.000 / 0.108$ \\
\hline$\Delta T 10 y r$ & $-0.029(0.02)$ & $-0.021(0.04)$ & $-0.087(0.20)$ & $0.000 / 0.097$ & $-0.029(0.02)$ & $-0.022(0.04)$ & $-0.083(0.21)$ & $0.000 / 0.097$ \\
\hline$\Delta T 30 y r$ & $-0.032(0.01)$ & $-0.028(0.03)$ & $-0.142(0.11)$ & $0.035 / 0.072$ & $-0.031(0.01)$ & $-0.029(0.03)$ & $-0.141(0.12)$ & $0.035 / 0.072$ \\
\hline
\end{tabular}

NOTE: Estimated standard errors are in parentheses.

change when monthly data were used. He interprets this result as being consistent with the expectations theory of the term structure, suggesting that "the anticipated rate changes are associated with expectations of further actions in subsequent months." 13 While market participants may revise their expectation of future rate changes in response to an unanticipated target change, we do not believe that they would do so in response to an expected target change. Consequently, we suspect there is another explanation for this result.
One possible explanation comes from noting that before 1994 there were relatively few occasions when the funds rate target and the discount rate were changed simultaneously. After 1994 things are very different. Of the 24 target changes considered in the post- 1993 period, 16 were accompanied by a change in the discount rate. Thornton (1996) found that the 3-month T-bill rate responded differently to target changes when the discount rate was

${ }^{13}$ Kuttner (2001, p. 541). 


\section{Figure 1}

\section{Poole/Rasche and Kuttner Measures of Unexpected Funds Rate Target Changes (Post-1993)}

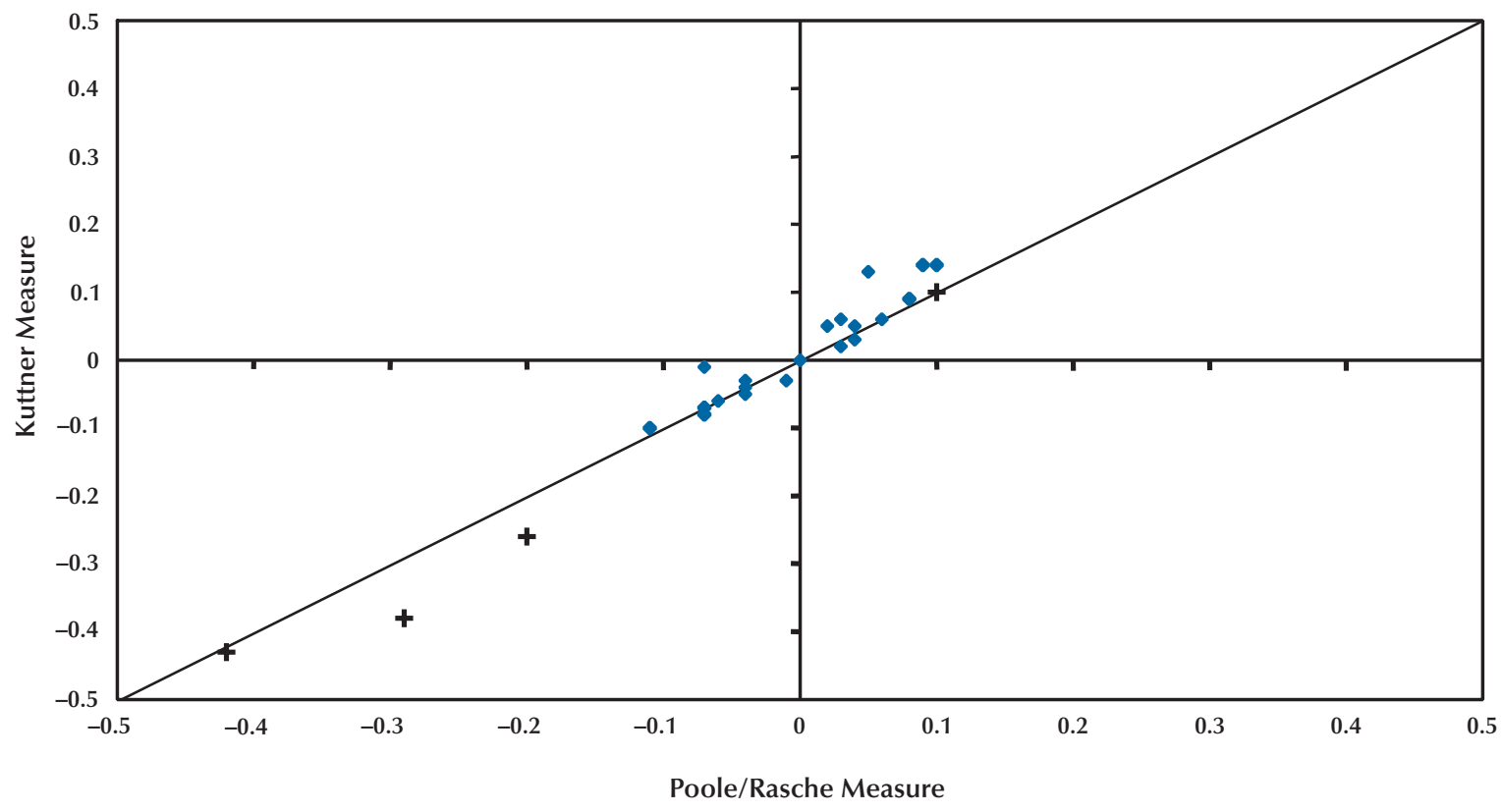

NOTE: + Denotes unexpected target changes associated with intermeeting changes in the funds rate target.

changed. Discount rate changes appear to have an independent effect on market rates. Hence, it is possible that the significant response to expected target changes (reported in Tables 3 and 4) is due to the fact that, on some occasions, the Fed provided additional information by simultaneously changing the discount rate.

To investigate this possibility, the equations were reestimated with target changes partitioned into those when the discount rate was changed and those when it was not. Specifically, the equation

$$
\Delta i_{t}=\alpha+\beta_{1} \Delta f f_{t}^{*}\left|\Delta d r+\beta_{1}^{\prime} \Delta f f_{t}^{*}\right| n o \Delta d r+\beta_{3} \Delta f f_{t}^{*} u+\varepsilon_{t}
$$

was estimated.

EV estimates of equation (11) are reported in Table 5. They suggest that changes in the funds rate target that are accompanied by changes in the discount rate provide additional (unanticipated) information. In the absence of such additional information, the market does not respond significantly to expected target changes. The market only responds to "expected" target changes when new information is simultaneously provided. In this case, the new information comes in the form of a discount rate change.

\section{THE MARKET REACTION TO UNEXPECTED TARGET CHANGES- PRE-1994}

To apply the Poole/Rasche and Kuttner methodology to target changes before 1994, we must first identify whether the market realized on the day of the event that a target change had occurred. To determine the market's knowledge of a target change, we read the front page and the Credit Markets column from the WSJ for at least two days after each change in the funds rate target. This procedure is complicated by the fact that there is some difference of opinion about when the funds rate target was changed. We started with a widely used series of target changes reported by the Federal Reserve Bank of New York. Recently, however, Thornton and Wheelock (2000) presented an alternative series prepared by the staff of the FOMC Secretariat's office. Before 1989 these series sometimes differ in the dating and magnitude of Fed actions. The dates considered are the union 


\section{Table 5}

EV Estimates with Target Changes Partitioned into Those That Were and Were Not Accompanied by a Change in the Discount Rate

\begin{tabular}{lccccc}
\multicolumn{5}{c}{$\Delta i_{t}=\alpha+\beta_{1} \Delta f f_{t}^{*}\left|\Delta d r+\beta_{1}^{\prime} \Delta f f_{t}^{*}\right| n o \Delta d r+\beta_{3} \Delta f f_{t}^{*} u+\varepsilon_{t}$} \\
Rate & $\alpha$ & $\beta_{1}$ & $\beta_{1}^{\prime}$ & $\beta_{3}$ & $\overline{\mathbf{R}}^{2} / \mathbf{s}$ \\
\hline$\Delta t b 3$ & $-0.122(0.11)$ & $0.071(0.03)$ & $0.075(0.06)$ & $0.738(0.30)$ & $0.577 / 0.088$ \\
$\Delta t b 6$ & $-0.035(0.01)$ & $0.033(0.04)$ & $0.098(0.08)$ & $0.605(0.23)$ & $0.509 / 0.076$ \\
$\Delta t b 12$ & $-0.036(0.01)$ & $0.005(0.05)$ & $0.112(0.08)$ & $0.546(0.21)$ & $0.370 / 0.081$ \\
$\Delta T 2 y r$ & $-0.029(0.02)$ & $-0.016(0.05)$ & $0.161(0.13)$ & $0.388(0.22)$ & $0.127 / 0.096$ \\
$\Delta T 5 y r$ & $-0.030(0.02)$ & $-0.064(0.05)$ & $0.142(0.14)$ & $0.256(0.25)$ & $0.000 / 0.105$ \\
$\Delta T 10 y r$ & $-0.026(0.02)$ & $-0.083(0.05)$ & $0.093(0.11)$ & $0.118(0.24)$ & $0.000 / 0.097$ \\
$\Delta T 30 y r$ & $-0.030(0.01)$ & $-0.072(0.04)$ & $0.055(0.10)$ & $0.002(0.10)$ & $0.014 / 0.107$
\end{tabular}

NOTE: Estimated standard errors are in parentheses.

of the two data sets. As a further check on the dating of the target change, we consulted the Report of Open Market Operations and Money Market Conditions (hereafter ROMO), which is prepared biweekly by the Manager of the Trading Desk of the Federal Reserve Bank of New York (the Desk). A detailed analysis of these differences led us to use the Secretariat's date of July 6, 1989, rather than the New York Fed's date of July 7 . The boxed insert provides a discussion of the more interesting dating conflicts, including the July 1989 conflict.

The market began to focus more attention on interest rates, including the federal funds rate, in 1987. Earlier in the decade of the 1980s, much of the discussion of policy was in terms of the effect of policy actions on the rate of money growth. Aware that Fed actions to increase or decrease reserve pressure influenced the federal funds rate, the market increasingly gauged policy by movements in the funds rate. However, market analysts frequently were unable to determine whether changes in the funds rate signaled a monetary policy action. In the early part of 1988, it appears that the market became more aware that the Fed was relying heavily on the funds rate to implement policy and market analysts began to surmise the Fed's intentions for the funds rate by observing Desk operations relative to the behavior of the funds rate.

Table 6 reports the amounts and dates of all funds rate target changes and the new effective target level reported by the Federal Reserve Bank of New York between August 1987 and December 1993.14 If there is a difference between the New York series and the Secretariat's series, the Secretariat's dating of the action is also indicated. The table also indicates whether the discount rate was changed. Under Chairman Greenspan the funds rate target was changed whenever the discount rate was changed. This was not the case previously; more often than not the discount rate and the funds rate target were changed on different days.

Despite the increased awareness that the Fed was paying attention to the funds rate in conducting monetary policy, there is little indication that the market was aware that the Fed was setting an explicit objective for the federal funds rate before 1989. We believe that the first time in the 1980s that market participants knew that policy action occurred was May 9, 1988, when the Desk injected fewer reserves than analysts expected. This action sparked speculation that the Fed was increasing its fight against inflation, and market analysts concluded that the action would cause the funds rate to trade at 7 percent or slightly higher. ${ }^{15}$

\footnotetext{
14 As Kuttner (2001) has noted, the target change that occurred at the December 1990 FOMC meeting was effectively revealed to the market with the announcement of a 50-basis-point cut of the discount rate on December 18. The announcement was made at 3:30 p.m., however, after the markets had closed. Consequently, this change is dated as December 19. It should also be noted that there are two dates in Table 6 that differ from those reported in Thornton and Wheelock (2000, Appendix B). The first is October 16, 1989; Thornton and Wheelock originally used October 18 . The second is January 9, 1991, originally dated January 8

${ }^{15}$ This is also one of the dates where there is discrepancy on exactly when the change was implemented. The Secretariat's series suggests that the change took place on May 7 . There is no indication that the market was aware of an action on that date, however.
} 


\section{CONFLICT IN THE DATING OF TARGET CHANGES}

There are a few cases, deserving of special attention, where there is conflict in the dating of the change in the federal funds rate target as reported by the New York Fed compared with the dating provided by the staff of the Secretariat. The first occurred in January 1989. The New York Fed suggests the funds rate target was increased by 25 basis points on January 5,1989 . The staff of the Secretariat is less precise, putting the change early in January. From our reading of the WSJ, it is apparent that the market was aware that the Fed changed policy before January 5; however, the precise date cannot be determined. On January 5 the WSJ merely indicates that analysts thought that the Fed had tightened credit earlier in the week. The Report of Open Market Operations and Money Market Conditions (hereafter, ROMO), however, clearly indicates that "on the second Thursday-January 5-the borrowing allowance was increased to $\$ 600$ million, in line with the Committee's decision at the December meeting." Hence, while the market thought that the Desk took actions consistent with changing policy in the first few days of January, the Desk indicates that the action was not taken until January 5 .

The second case occurred in July 1989. The New York Fed dates the change on July 7 , the Secretariat on July 6. Market analysts agree with the Secretariat staff's dating of the action and thought the Fed moved on the 6th, when the funds rate traded significantly below its previous trading range of 9.5 percent and the Desk made no attempt to offset the rate move. The ROMO indicates that "after the Committee's July 5-6 meeting, the borrowing allowance was set at $\$ 600$ million. This adjustment represented a slight intended easing of pressures on reserve positions, while also recognizing the recent rise in seasonal borrowing. (In the FOMC's discussion, 'unchanged' conditions of reserve availability were associated with a borrowing level of $\$ 650$ million; at any event, the Desk continued to view the borrowing allowance with some flexibility.)" The July 5-6 FOMC meeting adjourned at 11:50 a.m. Eastern time on July 6. Hence, it is very unlikely the Desk implemented the FOMC's decision on the 6th. Because of this, the New York Fed dates the change on July 7 , but because the decision was made on July 6 , the staff of the Secretariat dates the change on the 6th. Nevertheless, the market interpreted the Desk's failure to act on July 6, when the funds rate traded significantly below the previous trading level, as a policy action. While the decision is somewhat arbitrary, we have decided to use the Secretariat's dating of this target change.

The third case occurred in October 1989. The New York Fed dates the change on October 16 and the staff of the Secretariat dates it on October 19. Market analysts thought that the Fed had taken a (Continued on $p .75$ )
The market was not consistently aware of target changes at the time they happened until late 1989. This is about the time that the Fed began the practice of making target changes in multiples of 25 basis points. After late 1989 market analysts appear to have become adroit at identifying target changes when they occurred. In most cases analysts determined that the target had changed based on signals from the Desk. In many cases, however, the precise nature of the signal was not specified.

\section{Did Market Analysts Anticipate Fed Actions?}

In order to make the EV adjustment, we must again identify days on which the market was affected only by ambient news. Hence, the relevant question is, did market analysts anticipate Fed actions? The answer is yes, and no. There were many occasions when actions to increase or decrease pressure in the reserve market came as no surprise. Information on the state of the economy, inflation, or movements in the short-term interest rate fueled speculation that the Fed would soon change the discount rate or take other actions to alter the availability of credit. In this sense, there appears to be relatively few cases where the market was completely surprised by an action.

On the other hand, the precise dating of the Fed action nearly always surprised the market. Unlike the post-1993 period, we could find few instances where there was a widespread expectation that the Fed would take an action on a particular day. Moreover, we found no instance where there was a widespread expectation that the Fed would take an 
(Continued from $p .74$ )

policy action on October 16, when the Desk did not attempt to offset a significant decline in the federal funds rate. Indeed, fff $^{1}$ declined by 16 basis points on October 16 , suggesting that a very significant revision in the market's expectation for the federal funds rate occurred on that day. Market analysts also thought that the Fed took an action on the 19th, when the Desk added reserves despite the fact that the funds rate had drifted below the previous trading level.

The ROMO points to the source of the confusion. The ROMO for the maintenance period ending October 19, 1989, indicates that

The financial markets were jittery after the second weekend, in the wake of the 190-point plunge in the Dow Jones Industrial Average in late afternoon trading on October 13. New reports over the weekend had cited a "Fed official" as saying that the System would assure the provision of adequate liquidity. As a result, market participants widely expected a reserve injection on Monday and these anticipations appeared to exert additional downward pressure on the funds rate. The Desk responded to the unsettled conditions in financial markets by executing customer- related repurchase agreements on the second Monday and Tuesday [October $16 \&$ 17]. A final round of customer RPs was arranged on the settlement date [October 18], against the background of a bit firmer Federal funds rate that morning $-83 / 4$ percent - which appeared to stem partly from market uncertainties in the wake of Tuesday night's earthquake in San Francisco. Also, a background factor by this point was the decision discussed at Wednesday's FOMC conference call to begin implementing a slightly more accommodative reserve posture in light of recently incoming economic information: it was now expected that Fed funds trading would tend to center around $83 / 4$ percent.

The New York Fed and the staff of the Secretariat are obviously disputing the dating of the same policy action that could not have occurred on the same day. The discussion in the ROMO gives rather weak support to the Secretariat's dating, but the Desk's action of injecting reserves on October 16 when the funds rate was declining suggests that the Desk was pursuing a lower funds rate on Monday. Consequently, we use the New York Fed's dating of this action. action on the day the funds rate target was actually changed. Hence, in this respect, all target changes before 1994 were unexpected. Because the market frequently saw the need for an action, not all "unexpected" target changes resulted in large adjustments to federal funds futures rates.

We were unable to identify any occasion when the market correctly anticipated the Fed's action on a particular day, other than at scheduled FOMC meetings. Consequently, we determined the variance of the ambient news, $\sigma_{u}^{2}$, by using days when there was no headline announcement, no FOMC meeting, and no change in either the funds rate target or the discount rate.

The OLS and EV estimates for the pre-1994 period are presented in Table 7 . The response of Treasury rates for the pre-1994 period is somewhat larger than for the post-1993 period, especially at the longer end of the term structure. Moreover, the $\overline{\mathrm{R}}^{2}$ s indicate that a much larger proportion of the variance in Treasury rates on days when the market knew that the Fed changed the funds rate target is explained by unexpected target changes. This is particularly true at the very long end of the term structure where all rates respond significantly to unexpected target changes. Furthermore, as the efficient market hypothesis suggests, none of the rates responds significantly to anticipated target changes.

\section{INTERPRETING THE RESPONSE OF TREASURY RATES}

Interpreting the response of Treasury rates to unexpected changes in the funds rate target requires an economic structure. While the simple expectations hypothesis $(\mathrm{EH})$ of the term structure of interest rates is nearly always rejected, longer-term instruments are clearly forward looking. ${ }^{16}$ Consequently,

\footnotetext{
${ }^{16}$ For evidence of the $\mathrm{EH}$ when the short-term rate is the effective federal funds rate, see Hardouvelis (1988), Simon (1990), Roberds, Runkle, and Whiteman (1996), and Thornton (2002).
} 


\section{Table 6}

Knowledge of Fed Actions Obtained from Reading the Credit Markets Column of the Wall Street Journal

\begin{tabular}{|c|c|c|c|c|c|}
\hline Date & $\mathrm{ff}^{*}$ & $\Delta f f^{*}$ & Secretariat & $\begin{array}{c}\text { Poole/Rasche } \\
\text { shock }\end{array}$ & Knowledge \\
\hline 8/27/87 & 6.7500 & 0.1250 & & NA & No \\
\hline 9/03/87 & 6.8750 & 0.1250 & & NA & No \\
\hline $9 / 04 / 87^{+}$ & 7.2500 & 0.3750 & & NA & No \\
\hline 9/22/87 & & & 0.1250 & NA & No \\
\hline 9/24/87 & 7.3125 & 0.0625 & & NA & No \\
\hline 10/22/87 & 7.1250 & -0.1875 & & NA & No \\
\hline 10/23/87 & & & -0.3750 & NA & No \\
\hline 10/28/87 & 7.0000 & -0.1250 & & NA & No \\
\hline 11/04/87 & 6.8125 & -0.1875 & & NA & No \\
\hline 1/28/88 & 6.6250 & -0.1875 & & NA & No \\
\hline 2/10/88 & & & -0.1250 & NA & No \\
\hline 2/11/88 & 6.5000 & -0.1250 & & NA & No \\
\hline 3/29/88 & & & 0.2500 & NA & No \\
\hline 3/30/88 & 6.7500 & 0.2500 & & NA & No \\
\hline 5/07/88 & & & 0.2500 & NA & No \\
\hline 5/09/88 & 7.0000 & 0.2500 & & NA & Yes \\
\hline $5 / 25 / 88$ & 7.2500 & 0.2500 & & NA & No \\
\hline 6/22/88 & 7.5000 & 0.2500 & & NA & No \\
\hline 7/19/88 & 7.6875 & 0.1875 & & NA & No \\
\hline 8/08/88 & 7.7500 & 0.0625 & & NA & No \\
\hline $8 / 09 / 88^{+}$ & 8.1250 & 0.3750 & & NA & Yes \\
\hline 10/20/88 & 8.2500 & 0.1250 & & 0.00 & No \\
\hline 11/17/88 & 8.3125 & 0.0625 & & 0.07 & No \\
\hline 11/22/88 & 8.3750 & 0.0625 & & 0.07 & No \\
\hline 12/14/88 & & & 0.4000 & 0.02 & No \\
\hline 12/15/88 & 8.6875 & 0.3125 & & 0.05 & Yes \\
\hline 12/29/88 & 8.7500 & 0.0625 & & -0.06 & No \\
\hline Early 1/89 & & & 0.3125 & NA & Yes \\
\hline 1/05/89 & 9.0000 & 0.2500 & & 0.00 & No \\
\hline 2/09/89 & 9.0625 & 0.0625 & & 0.01 & No \\
\hline 2/14/89 & 9.3125 & 0.2500 & & 0.04 & Yes \\
\hline 2/23/89 & 9.5625 & 0.2500 & & 0.14 & Yes \\
\hline $2 / 24 / 89^{+}$ & 9.7500 & 0.1875 & & 0.14 & Yes \\
\hline 5/04/89 & 9.8125 & 0.0625 & & 0.02 & No \\
\hline 6/06/89 & 9.5625 & -0.2500 & & 0.01 & Yes \\
\hline 7/06/89 & & & -0.2500 & 0.03 & Yes \\
\hline 7/07/89 & 9.3125 & -0.2500 & & -0.05 & No \\
\hline 7/27/89 & 9.0625 & -0.2500 & & -0.06 & No \\
\hline 8/10/89 & 9.0000 & -0.0625 & & 0.02 & No \\
\hline
\end{tabular}




\section{Table 6 cont'd}

\section{Knowledge of Fed Actions Obtained from Reading the Credit Markets Column of the} Wall Street Journal

\begin{tabular}{|c|c|c|c|c|c|}
\hline Date & $f f^{*}$ & $\Delta \boldsymbol{f} \boldsymbol{f}^{*}$ & Secretariat & $\begin{array}{c}\text { Poole/Rasche } \\
\text { shock }\end{array}$ & Knowledge \\
\hline 10/16/89 & 8.7500 & -0.2500 & & -0.16 & Yes \\
\hline $10 / 19 / 89$ & & & -0.2500 & 0.00 & Yes \\
\hline $11 / 06 / 89$ & 8.5000 & -0.2500 & & 0.03 & No \\
\hline $12 / 19 / 89$ & & & -0.2500 & $0.00^{\ddagger}$ & No \\
\hline 12/20/89 & 8.2500 & -0.2500 & & $-0.17^{\ddagger}$ & Yes \\
\hline 7/13/90 & 8.0000 & -0.2500 & & -0.09 & Yes \\
\hline 10/29/90 & 7.7500 & -0.2500 & & -0.02 & Yes \\
\hline $11 / 14 / 90$ & 7.5000 & -0.2500 & & 0.02 & No \\
\hline $12 / 07 / 90$ & 7.2500 & -0.2500 & & -0.14 & Yes \\
\hline $12 / 19 / 90^{+}$ & 7.0000 & -0.2500 & & -0.16 & Yes \\
\hline 1/08/91 & 6.7500 & -0.2500 & & -0.10 & Yes \\
\hline $2 / 01 / 91^{+}$ & 6.2500 & -0.5000 & & -0.20 & Yes \\
\hline $3 / 08 / 91$ & 6.0000 & -0.2500 & & -0.13 & Yes \\
\hline $4 / 30 / 91^{+}$ & 5.7500 & -0.2500 & & -0.17 & Yes \\
\hline 8/06/91 & 5.5000 & -0.2500 & & -0.09 & Yes \\
\hline $9 / 13 / 91^{+}$ & 5.2500 & -0.2500 & & -0.04 & Yes \\
\hline 10/31/91 & 5.0000 & -0.2500 & & -0.05 & No \\
\hline $11 / 06 / 91^{+}$ & 4.7500 & -0.2500 & & -0.12 & Yes \\
\hline $12 / 06 / 91$ & 4.5000 & -0.2500 & & -0.11 & Yes \\
\hline $12 / 20 / 91^{+}$ & 4.0000 & -0.5000 & & -0.26 & Yes \\
\hline 4/09/92 & 3.7500 & -0.2500 & & -0.21 & Yes \\
\hline $7 / 02 / 92^{+}$ & 3.2500 & -0.5000 & & -0.32 & Yes \\
\hline 9/04/92 & 3.0000 & -0.2500 & & -0.20 & Yes \\
\hline
\end{tabular}

NOTE: ${ }^{+}$Indicates the target change was accompanied by a change in the discount rate.

‡The Poole/Rasche measure is unavailable on these days, so the Kuttner measure is reported.

it is reasonable to assume that the long-term rate is determined, at least in part, by the market's expectation of the funds rate target. The simple EH hypothesizes that the long-term rate is equal to the market's expectation for the overnight federal funds rate over the holding period of the long-term rate plus a constant risk premium, $\pi$, i.e.,

$$
i_{t}^{n}=(1 / n) \sum_{i=0}^{n-1} E_{t} f f_{t+i}+\pi^{n},
$$

where $i_{t}^{n}$ denotes the $n$-day maturity Treasury rate on day $t$ and $\pi^{n}$ denotes a maturity-specific constant risk premium. It is perhaps more reasonable to assume that there is a time-varying component to the risk premium, so that the EH can be more generally written as

$$
i_{t}^{n}=(1 / n) \sum_{i=0}^{n-1} E_{t} f f_{t+i}+\pi^{n}+\omega_{t}+v_{t}^{n},
$$

where $\omega_{t}$ denotes the unobserved time-varying component of the risk premium and $v_{t}^{n}$ denotes a random idiosyncratic shock to the $n$-day maturity Treasury rate.

Substituting (2) into (13) and taking the first difference yields

$$
\Delta i_{t}^{n}=(1 / n) \sum_{i=0}^{n-1}\left[E_{t} f f_{t+i}^{*}-E_{t-1} f f_{t+i-1}^{*}\right]+\Delta \omega_{t}+\Delta v_{t}^{n} .
$$

To see how our results can be interpreted, we 


\section{Table 7}

OLS and EV Estimates of the Response of Treasury Rates to Target Surprises Using the Poole/Rasche Measure (Pre-1994)

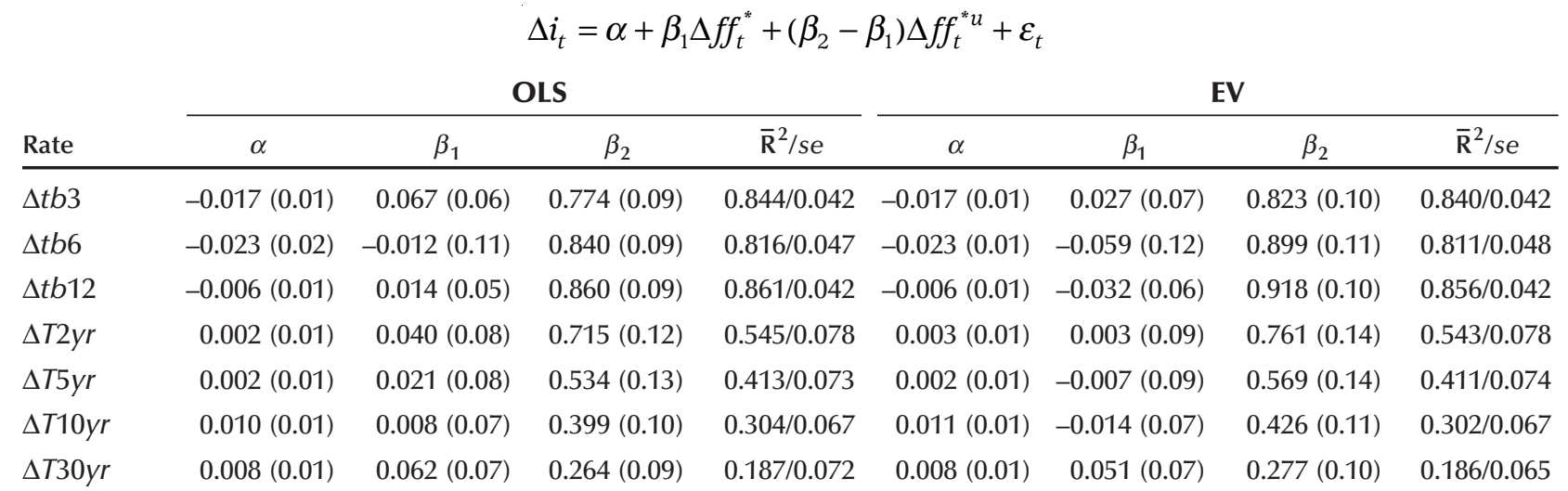

NOTE: Estimated standard errors are in parentheses.

impose the restriction that the market only responds to unexpected target changes so that equation (6) can be rewritten as

$$
\Delta i_{t}^{n}=\alpha+\beta_{2} \Delta f f_{t}^{*} u+\varepsilon_{t} .
$$

Given these assumptions, the OLS estimator of $\beta_{2}$ is equal to

(16)

$$
\begin{aligned}
& \hat{\beta}_{2}= \\
& \left.\frac{\frac{1}{T} \sum_{t=1}^{T}\left[(1 / n) \sum_{i=0}^{n-1}\left[E_{t} f f_{t+i}^{*}-E_{t-1} f f_{t+i-1}^{*}\right]+\omega_{t}+v_{t}\right]\left[\Delta f f_{t}^{*} u\right.}{\frac{1}{T} \sum_{t=1}^{T}\left[\Delta f f_{t}^{*} u\right.}\right]^{2}
\end{aligned} .
$$

The problem is that $f f_{t}^{*} u$ is unobservable. To see the potential problems associated with using the federal funds futures rate, assume that the $h$ month-ahead federal funds futures rate is equal to the market's expectation for the average effective federal funds rate $h$ months into the future, adjusted for term premiums and idiosyncratic shocks, i.e.,

$$
f f f_{t}^{h}=(1 / m) E_{t} \sum_{k=1}^{m} f f_{k}^{h}+\varphi^{h}+\theta_{t}^{h}+\eta_{t}^{h},
$$

where $\varphi^{h}+\theta_{t}^{h}$ denotes the potential constant and time-varying components of a term premium for the $h$-month-ahead federal funds futures rate, $f f_{k}^{h}$ denotes the effective federal funds rate on day $k$ of month $h$ in the future, and $\eta_{t}^{h}$ denotes an idiosyncratic shock to the $h$-month federal funds futures rate. Taking the first difference of (17) yields
(18)

$$
\Delta f f f_{t}^{h}=(1 / m) \sum_{k=1}^{m}\left[E_{t} f f_{k}^{h}-E_{t-1} f f_{k}^{h}\right]+\Delta \theta_{t}^{h}+\Delta \eta_{t}^{h} .
$$

Assuming that the target change $(\gamma)$ is expected to be constant over the next month and that $E_{t} f f_{k}^{1}=$ $E_{t} f f_{k}^{*}$, the Poole/Rasche measure of the unexpected target change is $\Delta f f f_{t}^{1}=\gamma+\Delta \theta_{t}^{1}+\Delta \eta_{t}^{1}$, so that $\gamma=$ $\Delta f f f_{t}^{1}-\Delta \theta_{t}^{1}-\Delta \eta_{t}^{1}$. Substituting this expression into (16) yields

$$
\begin{aligned}
& \hat{\beta}_{2}= \\
& \frac{\frac{1}{T} \sum_{t=1}^{T}\left[(1 / n) \sum_{i=0}^{n-1}\left[E_{t} f f_{t+i}^{*}-E_{t-1} f f_{t+i-1}^{*}\right]+\Delta \omega_{t}+\Delta v_{t}\right]\left[\gamma-\Delta \theta_{t}-\Delta \eta_{t}\right]}{\frac{1}{T} \sum_{t=1}^{T}\left[\gamma-\Delta \theta_{t}-\Delta \eta_{t}\right]^{2}} \cdot{ }^{2}
\end{aligned}
$$

Assume that (i) the idiosyncratic shocks are independent of each other and of the time-varying term premiums, (ii) $\hat{\rho}$ is an estimate of the coefficient of the correlation between the change in the timevarying components of the term premiums, and (iii) $s_{\Delta \omega}^{2}$ and $s_{\Delta \theta}^{2}$ are estimates of the variance of the time-varying components for the Treasury and federal funds futures rates, respectively. If participants in the Treasury market revise their expectation for the funds rate target permanently, i.e., $E_{t} f f_{t+i}^{*}$ $-E_{t-1} f f_{t+i-1}^{*}=\gamma$, for all $i$, (19) can be rewritten as

\footnotetext{
17 The maturity superscripts have been dropped for notational convenience.
} 


$$
\begin{aligned}
\hat{\beta}_{2} & =\frac{\frac{1}{T} \sum_{t=1}^{T}\left[\gamma+\Delta \omega_{t}+\Delta v_{t}\right]\left[\gamma-\Delta \theta_{t}-\Delta \eta_{t}\right]}{\frac{1}{T} \sum_{k=1}^{N}\left[\gamma-\Delta \theta_{t}-\Delta \eta_{t}\right]^{2}} \\
& =\frac{T \gamma^{2}-\hat{\rho} s_{\Delta \omega} s_{\Delta \theta}}{T \gamma^{2}+s_{\Delta \theta}^{2}+s_{\Delta \eta}^{2}} .
\end{aligned}
$$

If there are neither time-varying risk premiums nor idiosyncratic shocks to the federal funds futures rate, $\hat{\beta}_{2}=1$. To the extent that we have corrected for the bias due to common shocks, the estimate of $\hat{\beta}_{2}$ should be close to 1 if the market participants permanently revise their expectation for the funds rate target point-for-point with the unexpected target change and if the idiosyncratic variation in the 1 -month futures rate is relatively small.

Estimates of $\hat{\beta}_{2}$ will be less than 1 if the market believes that the change in the target will last for a period that is shorter than the maturity of the instrument. Note that the estimate of $\hat{\beta}_{2}$ could also be greater than 1 . This could occur if market participants believe that the unexpected target change will lead to further changes in the same direction. ${ }^{18}$ If the market correctly anticipates the magnitude of the Fed's action but misses the timing, the size of the response will depend on the extent to which the market missed the timing-the larger the miss, the larger the response.

The estimates of $\beta_{2}$ in Tables 3 and 7 for the post-1993 and pre-1994 periods suggest that Treasury rates respond significantly to unexpected changes in the Fed's funds rate target. For both the 3- and 6-month T-bill rates the estimated coefficient is not significantly different from 1 , suggesting that the market revises its expectation for the funds rate target several months into the future point-for-point with the unexpected change in the target. During the pre-1994 period, the estimated coefficients on the 12-month and 2-year rates are also not significantly different from 1, suggesting that the market revised its expectation for the funds rate target over a longer horizon before 1994. In most of these instances, however, the point estimates are quite different from 1. It is impossible to say whether this is due to missing the timing of the Fed's action or to the relative importance of idiosyncratic variation in the futures rate.

For both periods, the response of the Treasury rate to unexpected target changes declines as the term lengthens. For the post-1993 period, the response is not significantly different from zero for maturities beyond 12 months. Indeed, for the 10and 30-year rates the point estimates are essentially zero. In contrast, for the pre- 1994 period the response is statistically significant for all maturities.

One possible interpretation for the general result that the response declines as the maturity lengthens is that the market believes that the funds rate will stay at its new level for a relatively short period of time. For the pre-1994 period, the response is nearly the same for maturities up to 12 months and then declines. Kuttner (2001) and Cook and Hahn (1989) interpret this result to "mean reversion" of the federal funds rate. Specifically, they suggest that beyond one year, the market expects the funds rate to revert to its mean level. The cycles in the nominal federal funds rate are very long, however. It seems unlikely that the market would anticipate that the funds rate would start to return to its mean level in just over a year. Moreover, for the post-1993 period, the estimated coefficients begin to decline after three months. For this explanation to account for the post-1993 results, the market would have to anticipate mean reversion after three months - an incredibly short period.

\section{CASE STUDIES}

A potential problem in interpreting the estimate of $\beta_{2}$ arises from the fact that all interest rates are affected by publicly available information. Case studies can shed light on this and several other issues.

To illustrate the potential problem, note that (15) is actually

$$
\Delta i_{t}^{n}=\alpha+\beta\left[\Delta f f f_{t}^{1} \mid \Delta f f_{t}^{*} u \neq 0\right]+\varepsilon_{t} .
$$

Now assume that equation (21) is mistakenly estimated using days when there were no unexpected changes in the funds rate target, i.e.,

$$
\Delta i_{t}^{n}=\alpha+\beta\left[\Delta f f f_{t}^{1} \mid \Delta f f_{t}^{*} u=0\right]+\varepsilon_{t} .
$$

Substituting (14) and (18) into (22), it is easy to show that the OLS estimate of $\beta$ is equal to

$$
\hat{\beta}=\frac{\hat{\rho} s_{\Delta \omega} s_{\Delta \theta}}{s_{\Delta \theta}^{2}+s_{\Delta \eta}^{2}} .
$$

Estimates of $\beta$ will be zero if and only if $\hat{\rho}=0$. If the term premiums are positively correlated, the estimate of $\beta$ will be larger the larger is $\hat{\rho}$ and the smaller is the idiosyncratic variance in the federal funds

\footnotetext{
${ }^{18}$ It cannot be exactly zero because the term of the bill rate shortens from one day to the next.
} 


\section{Figure 2}

\section{Funds Futures for April 1994 FOMC Event}

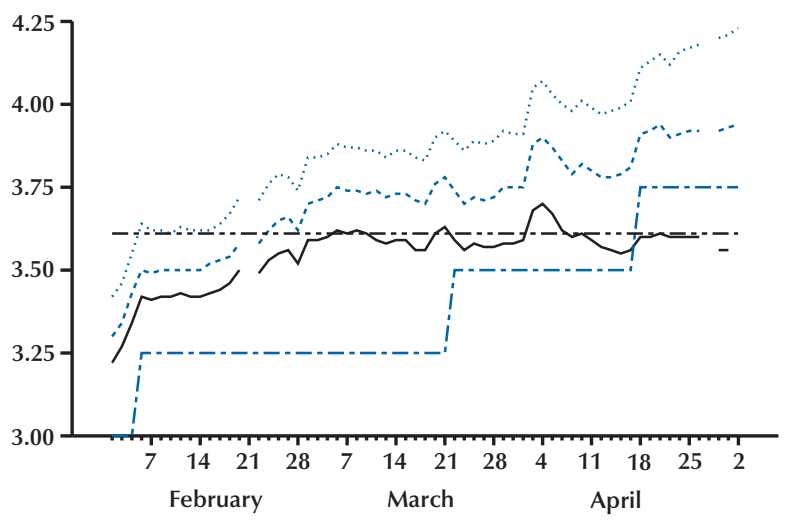

— Apr $1994 \quad$..... May $1994 \quad$....... Jun $1994 \quad$ - - - Target

-... Apr Average Target

futures rate. If the magnitude of $\hat{\rho}$ declines as the term to maturity on Treasury rates lengthens, so too will estimates of $\beta$.

Identifying times where there were unexpected changes in the funds rate target is critical for interpreting the results, because of the potential for correlation between changes in Treasury rates and changes in the federal funds futures rate even when there are no changes in the funds rate target or expectations thereof. We have been careful; nevertheless, it is important to check the robustness of our interpretation of the results. As a check on our interpretation, we undertook a case-by-case investigation of the response of federal funds futures rates to each unexpected target change noted in Table 2. In each instance, we examined the rates on federal funds futures contracts for the month of the event and for the months leading up to and just after the surprise events identified in Table 2.

Before discussing the findings in general, it is useful to get an idea of the methodology with two illustrative examples (a detailed analysis of each of the surprise events is presented in the appendix). The first example is for the intermeeting target change that occurred on April 18, 1994. The commentary indicated that the market anticipated that the Fed would raise the funds rate, but the timing of the April move was unexpected. For the period leading up to and just after the April 18, 1994, increase in the funds rate target, Figure 2 shows the rates on the April, May, and June federal funds futures contracts, the funds rate target, and the

\section{Figure 3}

\section{Funds Futures for May 1994 FOMC Event}

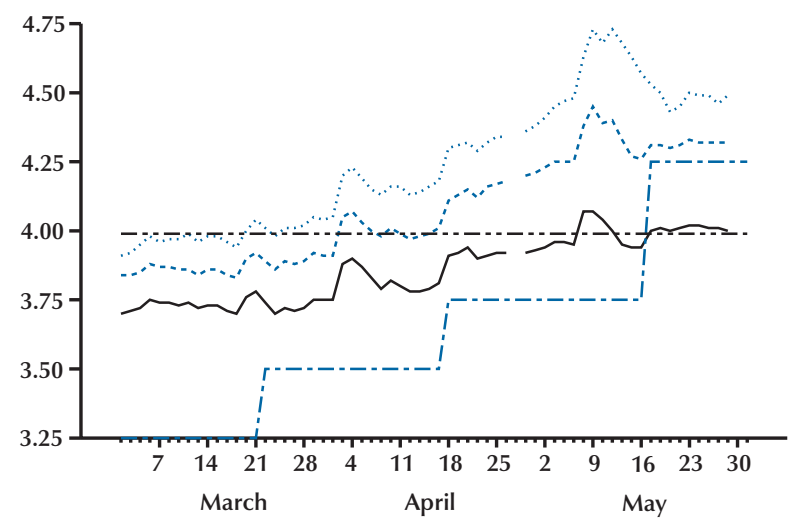

— May $1994 \quad$..... Jun $1994 \quad$....... Jul $1994 \quad$-.- Target -... May Average Target

average funds rate target for April. The average target is the weighted average of the target of 3.5 percent for 18 days and 3.75 percent for 12 days.

During March (at least as early as the release of the report on the employment situation for February 1994 on March 4), the prevailing expectation was as follows: there was a high probability of a 50-basis-point increase before the beginning of May, with an even higher intended funds rate on average during June. The increase in the funds rate target that occurred in March was expected and there was no revision of the market's expectation for the future funds rate target.

The situation after the April intermeeting move is very different. Figure 3 shows that there was a significant revision in the market's expectation for the funds rate in May and June immediately upon the Fed's April action. For most of the period subsequent to the intermeeting change in the intended funds rate in April, market participants assigned a high probability to an additional increase of 50 basis points at the May FOMC meeting. Market participants had come to expect that a 50-basis-point increase over the target established in April would prevail during May and were assigning a high probability of an additional 25-basis-point increase at the June FOMC meeting. In late March, expectations of even higher intended funds rates for April, May, and June prevailed; however, these expectations were reversed by early April. Consistent with our interpretation of the regression results, the April action appears to have caused market participants to significantly 


\section{Figure 4}

\section{Funds Futures for March 1994 FOMC Event}

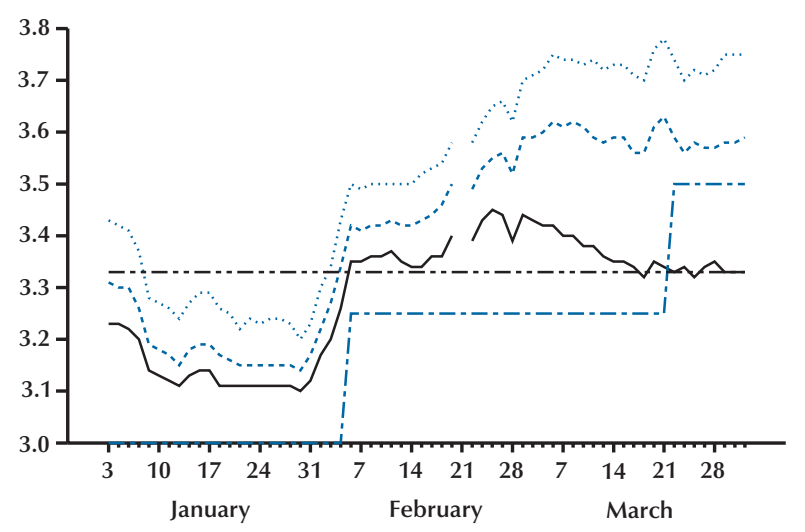

— Mar $1994 \quad$-.... Apr 1994

_... Mar Average Target

revise their expectations for the funds rate in May and June.

For 9 of the 14 target changes where our analysis of market commentary suggested that the market was surprised by the Fed's action, there was a clear indication that the market revised its expectation for the funds rate out two months. On one of these occasions (July 6, 1995), however, the market's expectation for the funds rate out two months was significantly revised in the weeks following the target change.

There appeared to be no significant revision of the market's expectation for the funds rate out two months on five occasions. One of these occasions occurred on March 22, 1994, shown in Figure 4. The market had revised its expectation for the funds rate in May, a couple of weeks prior to the March FOMC meeting. While our analysis of the commentary suggested that the March action was a surprise, both the Poole/Rasche and Kuttner measures of the unexpected target change were very small. Hence, it may be that the commentary did not reflect the true market expectations at the time of the action.

Another instance when there was no revision of the market's expectation occurred on March 20, 2001, shown in Figure 5. At the time the FOMC reduced the funds rate target by 50 basis points, market participants were anticipating a 75 -basispoint reduction; however, there was no immediate revision of the market's expectation following the announcement.

On three of the five occasions, the Poole/Rasche

\section{Figure 5}

Funds Futures for March 2001 FOMC Event

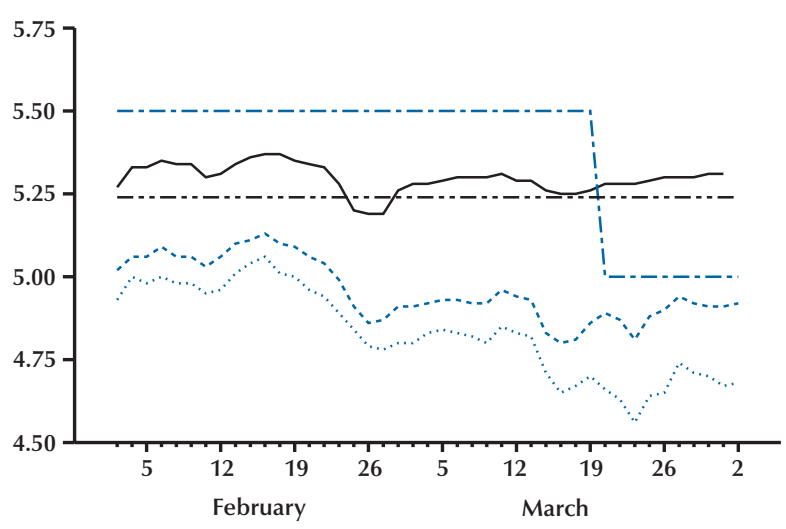

— Mar $2001 \quad$-.... Apr $2001 \quad$....... May $2001 \quad$ - - - Target

_... Mar Average Target

measure of the unexpected target change was 6 basis points or less-about two standard deviations of the variation in this measure associated with ambient news, suggesting that these actions were perhaps less of a surprise than the market commentary suggested. Moreover, on all occasions when the Poole/Rasche measure was larger than 10 basis points, the market appeared to revise its expectation for the funds rate at least two months out, suggesting that market participants might not revise their longer-run outlook for the funds rate target except in cases where they make a relatively large error in forecasting the Fed's action.

Market participants should not only revise their expectations when there is a surprise change in the funds rate, but also when they are surprised that the target was not changed. We identified only four such events. Our analysis suggests that of these four cases, three were instances when market participants revised their expectations for the future federal funds rate when the Fed failed to act as expected.

The most dramatic of these occurred in September 1996. The commentary indicated that market participants expected an FOMC action. Figure 6 shows the rates on the September, October, and November futures rate contracts before and after the September 1996 meeting. Both the futures rates and the market commentary suggest that market participants were expecting the FOMC to raise the target at the September FOMC meeting and were expecting additional subsequent increases. When the FOMC unexpectedly left the target unchanged, 


\section{Figure 6}

\section{Funds Futures for September 1996 FOMC Event}

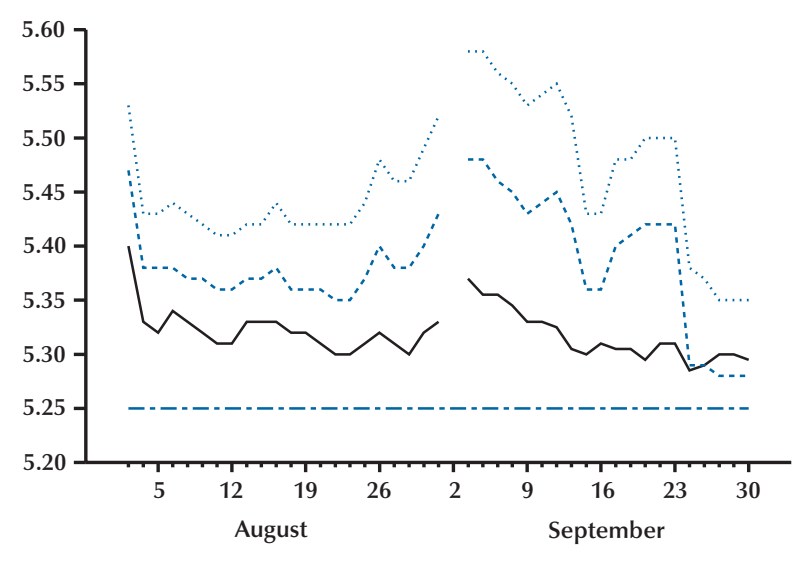

Sep 1996

..... Oct 1996

Nov 1996

--- Target

market participants significantly revised down their expectations for the funds rate in October and November. In the three cases where the Fed's inaction prompted markets to revise their longer-term expectations for the funds rate, the revision in expectations appears to be large relative to those cases where the FOMC took a surprise action. This finding is consistent with our previous interpretation in that, if the market expects a 25-basis-point change in the target and the FOMC does nothing, the unexpected action is relatively large.

The exception occurred in September 1994, shown in Figure 7, when the surprise decision not to change the rate at the FOMC meeting of September 27,1994 , had essentially no effect on the market's expectation for the federal funds rate in October and November.

\section{DOES GREATER TANSPARENCY HELP?}

The FOMC has made a number of procedural changes that should have helped the market anticipate policy actions. Analysis of the period before the 1994 implementation of the practice of announcing target changes is hampered by the fact that most target changes were made during the intermeeting period. Because the market could never be sure when a change was most likely to occur, market commentary never predicted the date or the magnitude of Fed actions before 1994. Hence, market commentary at that time cannot be used to determine target changes that were or were not expected,

\section{Figure 7}

\section{Funds Futures for September 1994 FOMC Event}

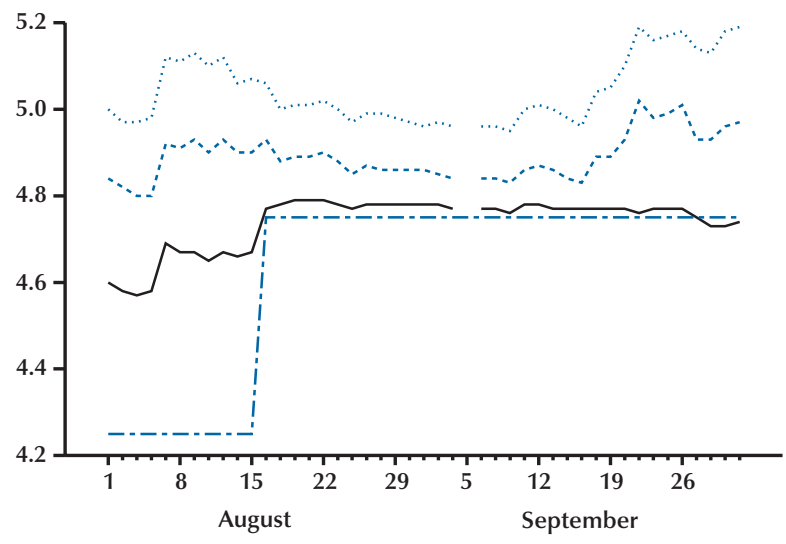

— Sep $1994 \quad$-.... Oct $1994 \quad$........ Nov $1994 \quad$ Nov - Target

as was done for the post-1993 period. Table 2, however, shows that for actions since 1994 that were not surprise actions, the Poole/Rasche measure of the unexpected target change was nearly always less than 6 basis points (about two estimated standard deviations of the variation in the 1 -month futures rate associated with ambient news). Hence, one way to determine expected target changes is to assume that the market anticipated the Fed's action when the Poole/Rasche measure of the unexpected target change is 6 basis points or smaller. Using this criterion, of the 24 target changes before 1994 that the market was aware had occurred, only 6 were anticipated; 18 target changes were unanticipated.

Moreover, if one assumes that changes in the current or 1-month federal funds futures rate measures the degree of the unexpected target change, there were only three instances, on days when the market knew that the target had been changed, when there were large unexpected target changes. All three of these are associated with intermeeting target changes.

Using the same criterion for the post-1993 period indicates that 10 of the 24 target changes were unanticipated. Our analysis of market commentary suggested that 14 target changes were unanticipated, but we concluded that the market anticipated the FOMC's action only if market participants correctly anticipated the size and the timing of the action.

While the above analysis is simple, it suggests that the market has been able to better forecast Fed 


\section{Figure 8}

Funds Futures for March 2000 FOMC Event

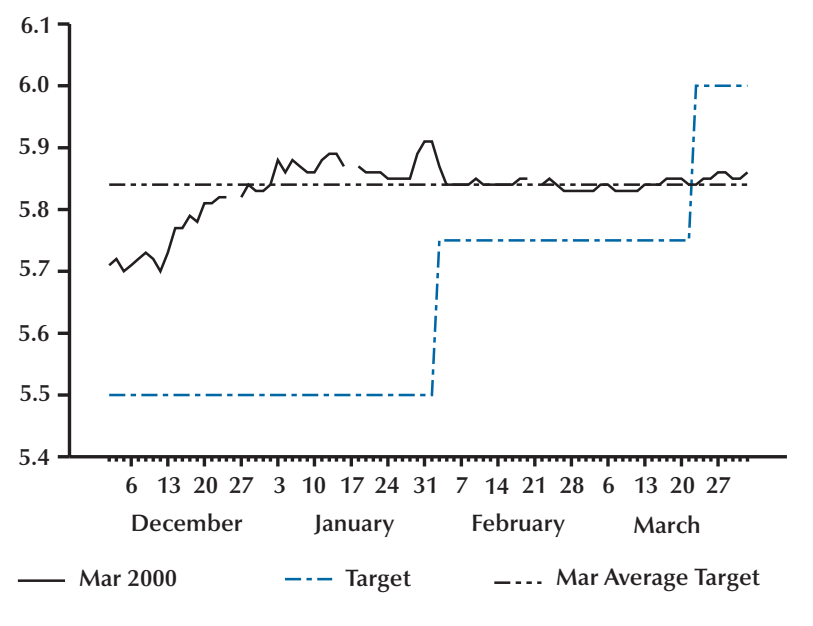

actions since the 1994 procedural change. In this regard, more transparency appears to help. This finding is not too surprising, however, since it is reasonable to expect that the market does a better job of anticipating policy actions when the timing of those actions is somewhat constrained by the FOMC's practice. Hence, somewhat more compelling evidence of the value of transparency can be obtained by determining whether the market is better able to predict Fed actions further in advance.

\section{How Far in Advance Does the Market Anticipate Fed Actions?}

Our results suggest that after 1994, market participants usually have anticipated changes in the funds rate target by the time they have occurred. The more transparent the Fed is, the further in advance the market should be able to predict policy actions. To get an idea of how far in advance the market anticipates Fed actions, we once again use the case study approach. Specifically, we plot (i) the rate on the federal funds futures contract for the month of target changes that we classified as "no surprise" in Table 2 and (ii) the average federal funds rate target for that month. Care must be taken because of the possibility of changes in the term premium. Nevertheless, if the market correctly anticipates the event, the rate on the federal funds futures contract for the month of the event should move to the level of the average effective federal funds rate before the event and stay close to that rate until the time of the event.

\section{Figure 9}

Funds Futures for June 1999 FOMC Event

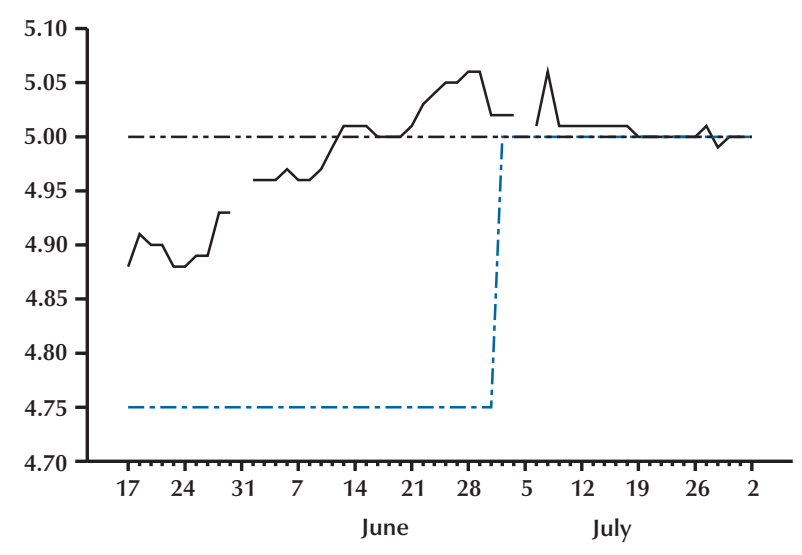

_ Jul $1999 \quad$ _- - Target _ - Jul Average Target

\section{Figure 10}

Funds Futures for August 1999 FOMC Event

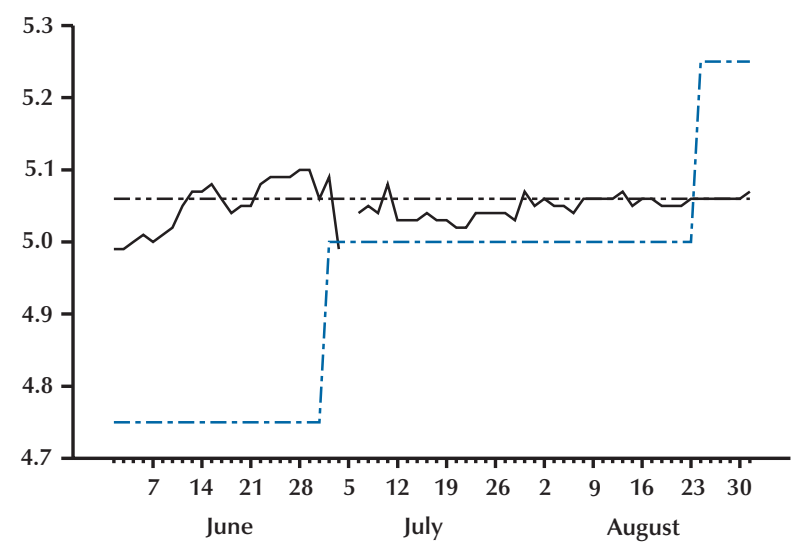

— Aug $1999 \quad$--- Target _-.. Aug Average Target

There were ten such events during the post 1993 period. Of these, our analysis suggests that on seven of these occasions the market anticipated the change two or more weeks in advance. For the change on March 21, 2000, shown in Figure 8, market participants appear to have anticipated the action about 12 weeks in advance. Indeed, before Christmas 1999 market participants correctly anticipated both the February and March actions.

Two of the more remarkable cases are associated with the target changes that occurred on June 30 and August 24, 1999. Figures 9 and 10 show the July 


\section{Figure 11}

Funds Futures for July 1989 FOMC Event

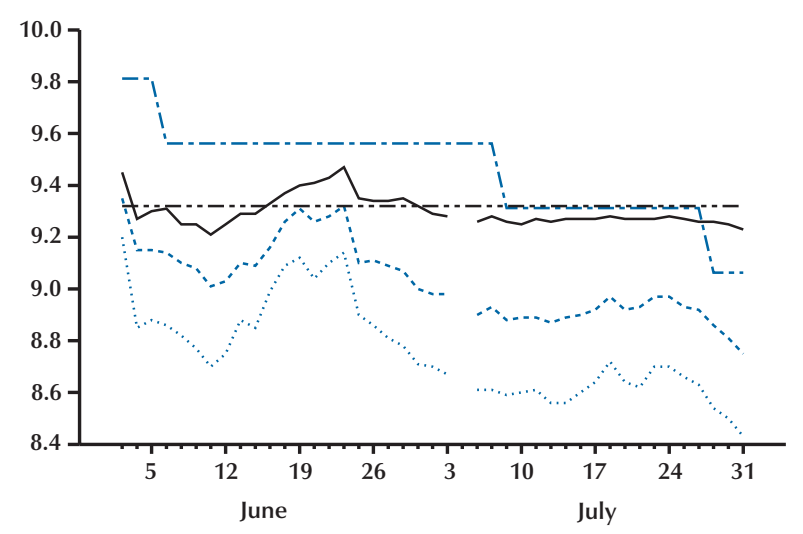

— Jul $1989 \quad$-.... Aug $1989 \quad$...... Sep $1989 \quad$-.- Target

-... Jul Average Target

and August federal funds futures rates and the average effective funds rate target for those months, respectively. By early June the market had come to expect not only the action taken on June 30, but the action taken on August 24 as well.

On the remaining three occasions, the actions appear not to have been expected until just days prior to the meetings. Hence, while the commentators were correct that these actions were widely anticipated, it appears that the market did not figure out what the FOMC was about to do until just days before the meeting.

To see whether the market's ability to predict Fed actions has improved since the beginning of 1994, we considered the six instances prior to 1994 where the market expected the Fed's action, using the criterion that the market expected the action if the Poole/Rasche measure of the unexpected target change is 6 basis points or less. Trading in the federal funds futures contracts began only two months prior to one of these occasions, December 1988. Moreover, there was no evidence that the market was aware that the Fed was targeting the funds rate at that time. For both of these reasons, analysis of this event is inappropriate.

Of the remaining five instances, there is only one instance, July 6, 1989, when the market appears to have anticipated the Fed's action well in advance. ${ }^{19}$ Figure 11 suggests that the 25-basis-point target change made at that time was anticipated by early June.

This analysis also supports the conclusion that transparency is important. After 1994, not only is the market better able to anticipate when the Fed will act, but, more importantly, there is some evidence that the market is able to predict those actions further in advance. Greater clarity should enable the market to better predict how the Fed is likely to respond to incoming information about economic fundamentals.

\section{DISCUSSION}

This paper investigates the extent to which market participants anticipate Fed actions, focusing on the period since the late 1980s. This period is nearly ideal. The Fed has been explicitly targeting the overnight federal funds rate during the entire period that the federal funds futures rate has been available to measure the market's expectation for the federal funds rate and, consequently, the funds rate target.

A natural way to proceed in this environment is to use the change in the futures rate as a proxy for the unexpected change in the funds rate target and then estimate the response of longer-term rates to the unexpected target change. A significant response of longer-term rates suggests that the unexpected change in the funds rate target caused markets to revise their longer-term expectations for the funds rate. While this procedure can provide useful information about how market participants revise their longer-run expectations, we note that care is required. For one thing, there is a measurement error associated with using the change in the futures rate to proxy the unexpected target change; it arises because idiosyncratic and other shocks cause variation in federal funds futures rates even when there are no changes in the funds rate target. This measurement error also can bias down the estimated response of other rates to the unexpected target change. In addition, this procedure requires that market participants know that the Fed has changed its funds rate target. If market participants do not know that the target has been changed, the change in the futures rate does not reflect the unexpected target change. This problem, of course, applies to the pre-1994 period when target changes were not announced.

Accounting for both of these problems, we estimate the response of Treasury rates of various maturities from 3 months to 30 years to unexpected target changes for periods before and after the

\footnotetext{
${ }^{19}$ The figures for the other four dates and for December 1988 are presented in the appendix.
} 
FOMC's 1994 procedural change. We find that the response of the 3-month T-bill rate is nearly identical before and after this procedural change. The magnitude and significance of the response of longer-term rates, however, declines after this procedural change. One possible explanation for the smaller response of longer-term rates is that the Fed has been more transparent about its longer-run policy intentions. Under this interpretation, the market would have relatively firm expectations that the Fed will change the funds rate target at some point in the future, but may have less-firm expectations of exactly when that change will occur. If only the timing of the target changes were unexpected, shorter-term futures rates would respond more to announcements of a target change than would longer-term rates.

We note that the interpretation of the response of Treasury rates to unexpected changes in the funds rate target is complicated by the possibility that all forward-looking rates might respond to common information, such as information that alters the market's expectation of the term premium. For this reason, extreme care must be exercised in identifying unexpected changes in the funds rate target. To address this issue, we undertake a case-by-case analysis of occasions when market commentary indicted that the market was surprised by the Fed's action or inaction. This analysis suggests that, in most of those cases, market participants revised their expectations for the funds rate at least two months out in response to an unexpected target change. Moreover, there is some indication that the larger the unexpected target change, the more likely it is that the market will revise its expectation for the funds rate.

Our most important finding is that greater transparency appears to help. Not only is the market better able to anticipate funds rate target changes, but it appears that the market is able to anticipate such changes further in advance. This is important since changes in the funds rate target can have a significant effect on economic variables only by generating changes in longer-term interest rates. The Fed can only affect long-term rates by affecting market participants' expectations for the future funds rate. The further in advance the market can anticipate changes in the funds rate, other things the same, the larger will be the corresponding changes in longer-term rates. Moreover, in such an environment, market responses in anticipation of policy actions begin to stabilize the economy long before the policy actions themselves occur.
The interaction of economic policy and market expectations has been a core feature of macroeconomics for 30 years. In this paper we documented the substantial change in the predictability of monetary policy that occurred in 1994. The period since 1994 has also been one of remarkable economic stability. We believe that the greater transparency of monetary policy has contributed to this outcome.

\section{REFERENCES}

Cook, Timothy and Hahn, Thomas. "The Effect of Changes in the Federal Funds Rate Target on Market Interest Rates in the 1970s." Journal of Monetary Economics, November 1989, 24(3), pp. 331-51.

Goodfriend, Marvin. "Monetary Mystique: Secrecy and Central Banking." Journal of Monetary Economics, January 1986, 17(1), pp. 63-92.

Hardouvelis, Gikas A. "The Predictive Power of the Term Structure During Recent Monetary Regimes.” Journal of Finance, June 1988, 43(2), pp. 339-56.

Hoover, Kevin D. and Jorda, Oscar. "Measuring Systematic Monetary Policy." Federal Reserve Bank of St. Louis Review, July/August 2001, 83(4), pp. 113-37.

Johnston, J. Econometric Methods. New York: McGraw-Hill, 1963.

Kuttner, Kenneth N. "Monetary Policy Surprises and Interest Rates: Evidence from the Fed Funds Futures Market." Journal of Monetary Economics, June 2001, 47(3), pp. 523-44.

Lucas, Robert E. Jr. "Econometric Policy Evaluation: A Critique.” Journal of Monetary Economics, 1976, 1(2), pp. 19-46.

McCallum, Bennett T. "Monetary Policy Analysis in Models Without Money." Federal Reserve Bank of St. Louis Review, July/August 2001, 83(4), pp. 145-60.

Meyer, Laurence H. “Does Money Matter?” Federal Reserve Bank of St. Louis Review, September/October 2001, 83(4), pp. $1-15$.

Poole, William and Rasche, Robert H. "Perfecting the Market's Knowledge of Monetary Policy." Journal of Financial Services Research, December 2000, 18(2-3), pp. 255-98. 
Rasche, Robert H. "The World of Central Banking: Then and Now," in Reflections on Economics: Essays in Honor of Martin M.G. Fase. Amsterdam: De Nederlansche Bank NV, 2001.

Roberds, William; Runkle, David and Whiteman, Charles $\mathrm{H}$. "A Daily View of Yield Spreads and Short-Term Interest Rate Movements." Journal of Money, Credit, and Banking, February 1996, 28(1), pp. 34-53.

Robertson, John C. and Thornton, Daniel L. "Using Federal Funds Futures Rates to Predict Federal Reserve Actions." Federal Reserve Bank of St. Louis Review, Novemberl December 1997, 79(6), pp. 45-53.

Simon, David P. "Expectations and the Treasury Bill-Federal Funds Rate Spread over Recent Monetary Policy Regimes.” Journal of Finance, June 1990, 45(2), pp. 467-77.

Taylor, John B. "Expectations, Open Market Operations, and Changes in the Federal Funds Rate." Federal Reserve Bank of St. Louis Review, July/August 2001, 83(4), pp. 3347.
Thornton, Daniel L. "The Conventional Test of the Expectations Theory: Resolving Some Anomalies at the Short End of the Term Structure." Unpublished manuscript, Federal Reserve Bank of St. Louis, February 2002.

"Does the Fed's New Policy of Immediate Disclosure Affect the Market?" Federal Reserve Bank of St. Louis Review, November/December 1996, 78(6), pp. 77-86.

and Wheelock, David C. "A History of the Asymmetric Policy Directive." Federal Reserve Bank of St. Louis Review, September/October 2000, 82(5), pp. 1-16.

Whitesell, William; Lange, Joe and Sack, Brian. "Anticipations of Monetary Policy in Financial Markets.” Unpublished manuscript, Board of Governors of the Federal Reserve System, March 2001.

Woodford, Michael. "Monetary Policy in the Information Economy." Unpublished manuscript, August 2001.

\section{Appendix}

\section{Figure A1-A}

\section{Funds Futures for December 1994 FOMC Event}

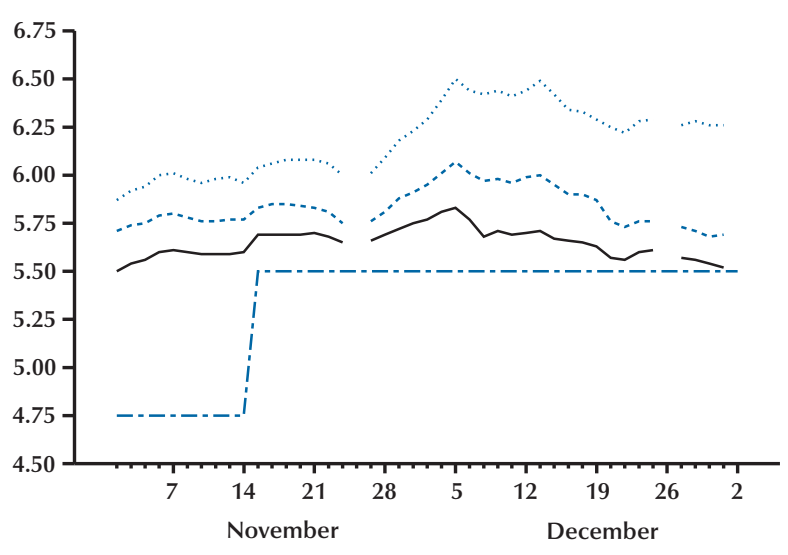

_ Dec $1994 \quad$-.... Jan $1995 \quad$....... Feb $1995 \quad$ - - - Target

\section{Figure A1-B}

\section{Funds Futures for May 1997 FOMC Event}

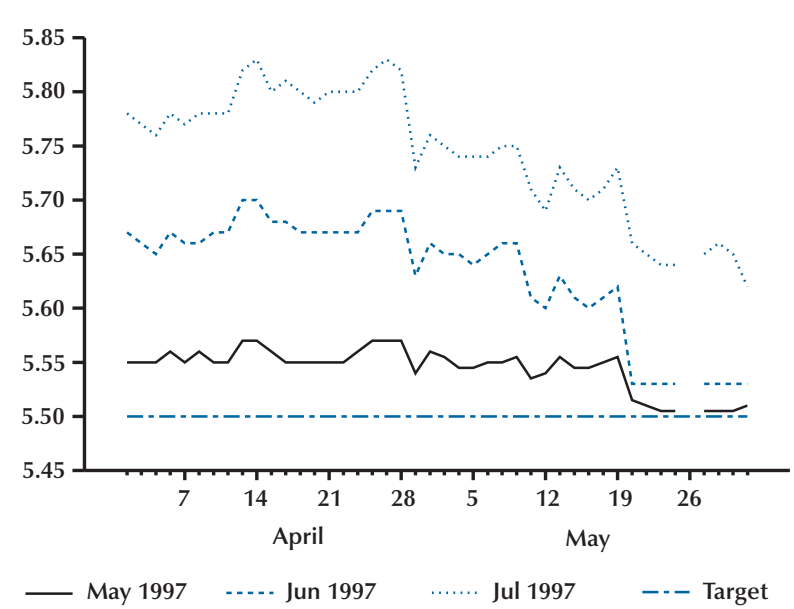




\section{Figure A2-A}

Funds Futures for August 1994 FOMC Event

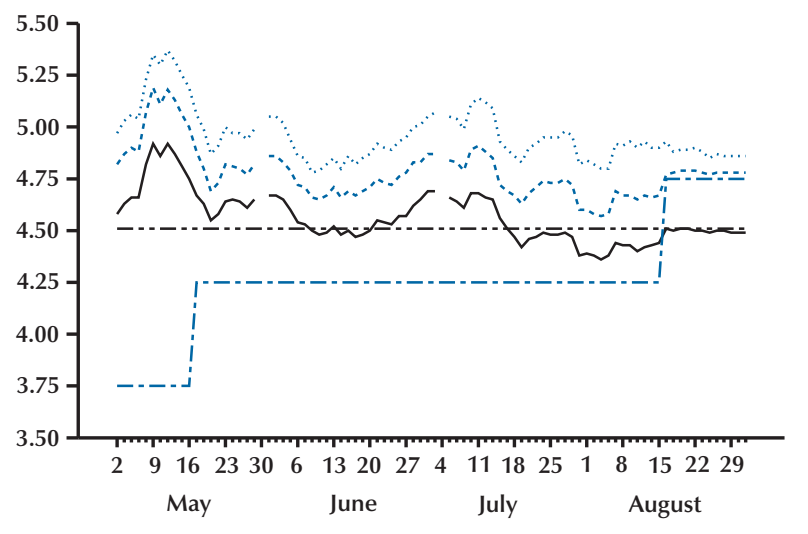

— Aug $1994 \quad$..... Sep 1994

Oct $1994 \quad---$ Target

-... Aug Average Target

\section{Figure A2-C}

\section{Funds Futures for July 1995 FOMC Event}

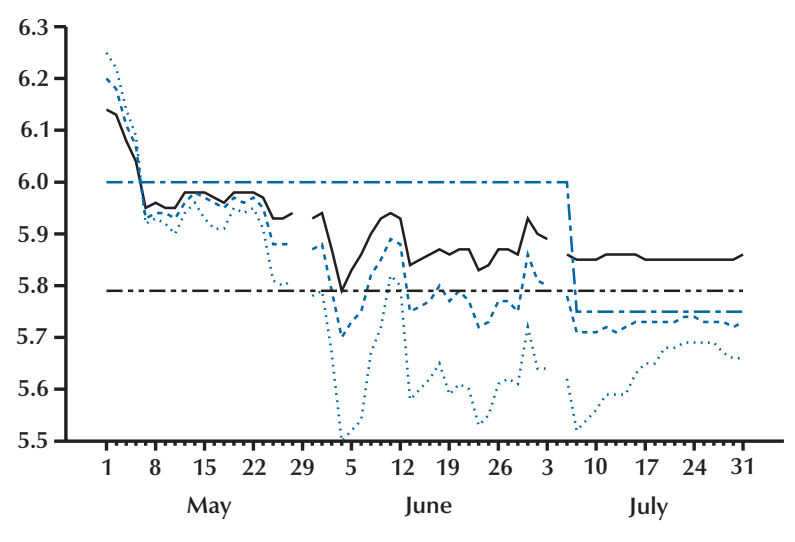

— Jul $1995 \quad$..... Aug $1995 \quad$...... Sep $1995 \quad$-.- Target

-... Jul Average Target

\section{Figure A2-B}

Funds Futures for November 1994 FOMC Event

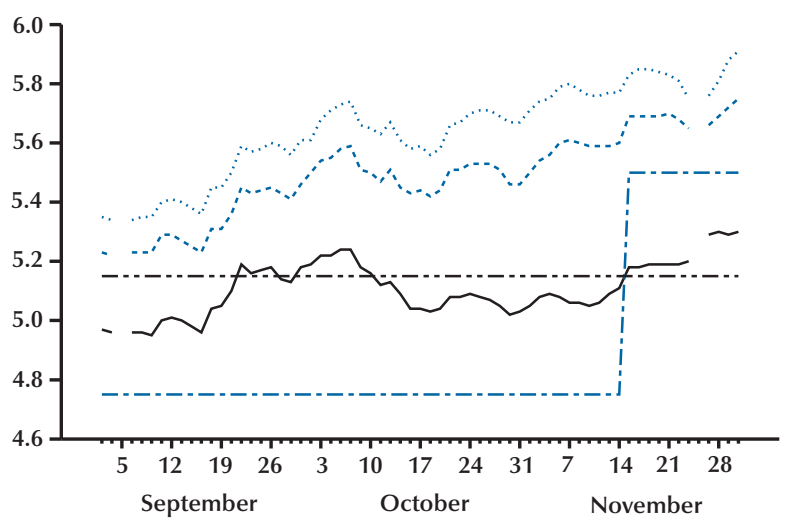

— Nov $1994 \quad$-.-. Dec $1994 \quad$....... Jan $1995 \quad$--- Target

-... Nov Average Target

\section{Figure A2-D}

\section{Funds Futures for December 1995 FOMC} Event

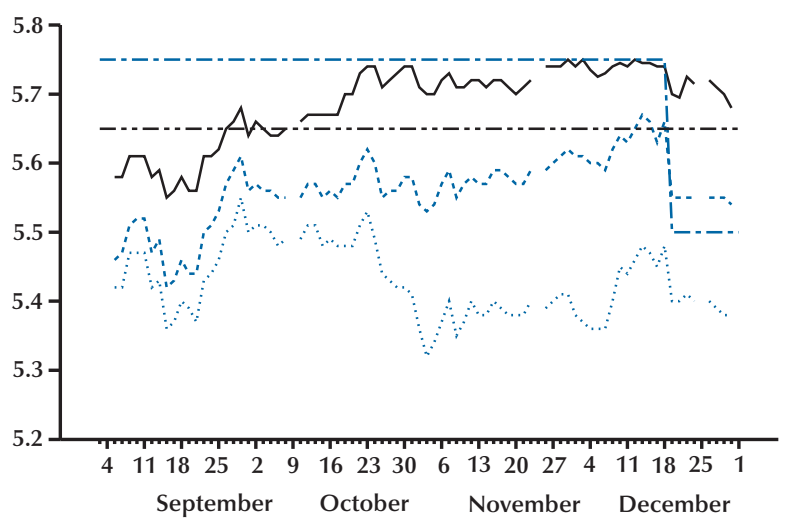

- Dec 1995

.... Jan 1996

Feb 1996

--- Target 


\section{Figure A2-E}

Funds Futures for January 1996 FOMC Event

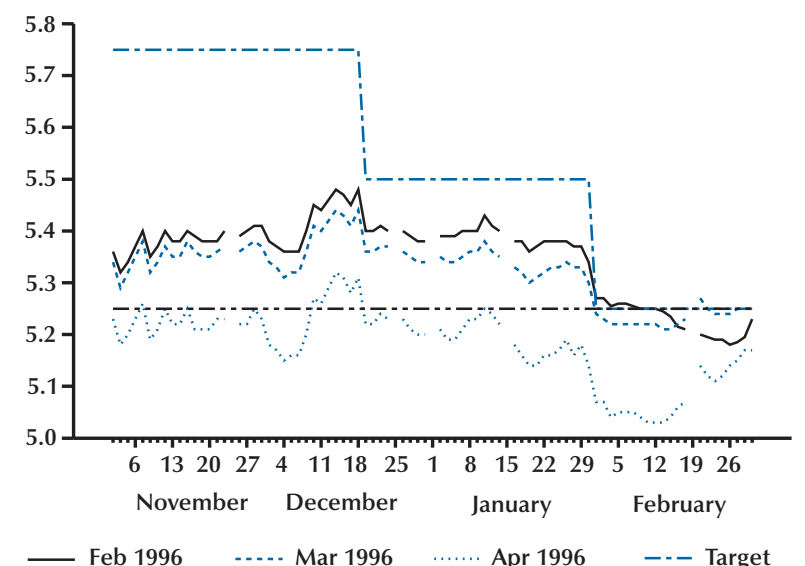

-... Feb Average Target

\section{Figure A2-G}

\section{Funds Futures for November 1998 FOMC} Event

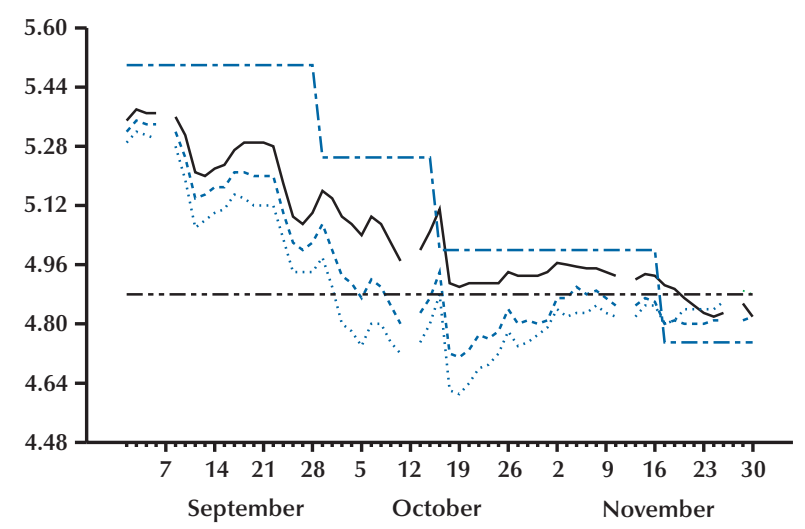

— Nov $1998 \quad$ _. . - . Dec $1998 \quad$....... Jan $1999 \quad$ - - - Target

_... Nov Average Target

\section{Figure A2-F}

Funds Futures for October 1998 FOMC Event

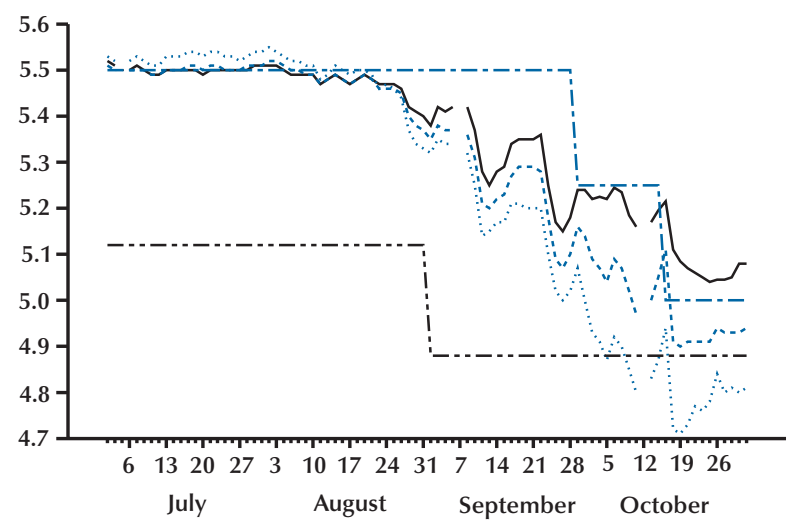

— Oct $1998 \quad$ - - - N Nov $1998 \quad$ …... Dec $1998 \quad$ - - - Target

-... Oct Average Target

\section{Figure A2-H}

\section{Funds Futures for November 1999 FOMC} Event

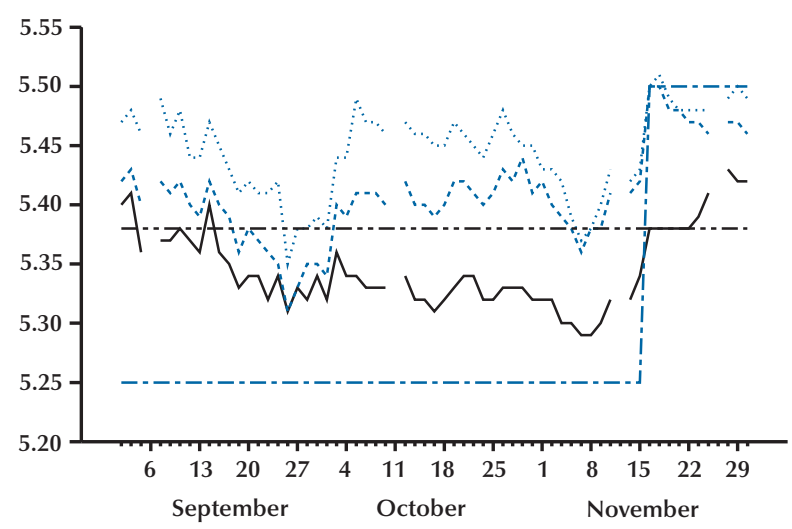

— Nov 1999 -.-.. Dec 1999

Jan $2000 \quad---$ Target

_. . - Nov Average Target 


\section{Figure A2-I}

Funds Futures for January 2001 FOMC Event

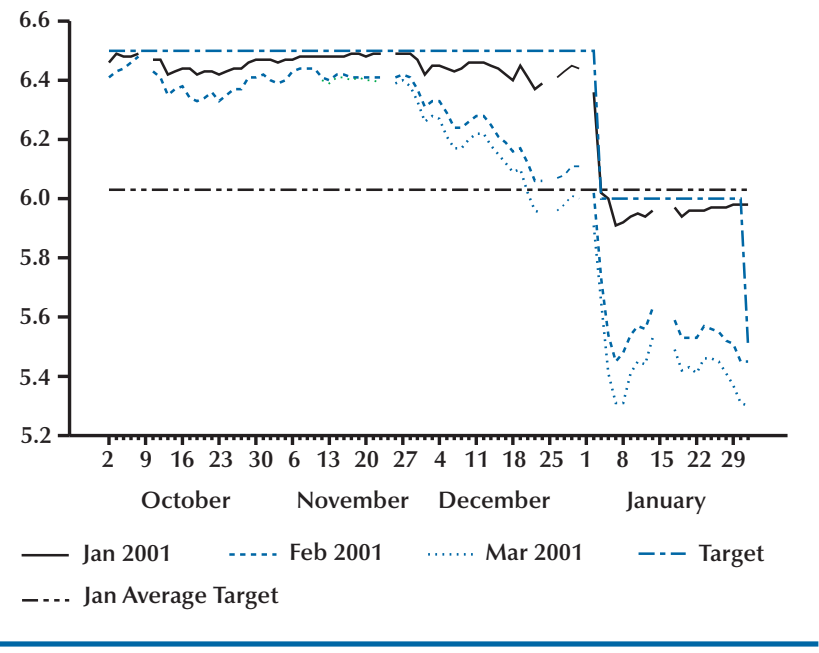

\section{Figure A2-J}

Funds Futures for April 2001 FOMC Event

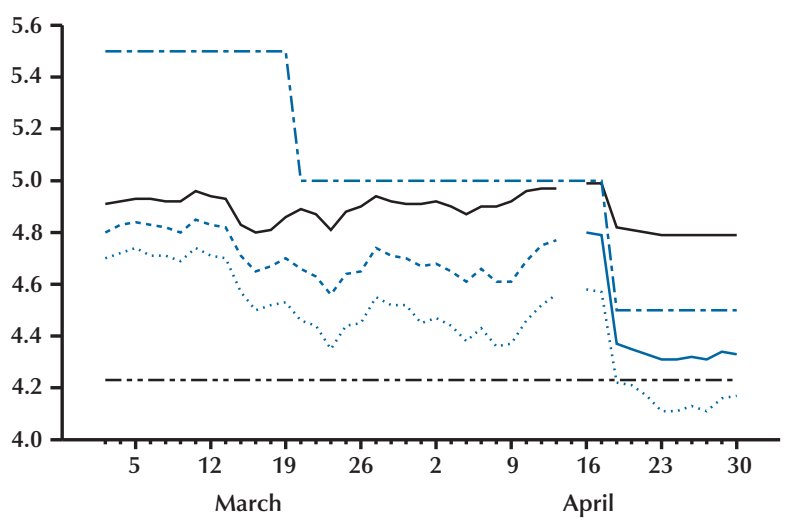

— Apr $2001 \quad$..... May $2001 \quad$....... Jun $2001 \quad$-.- Target

-... Apr Average Target 


\section{Figure A3-A}

Funds Futures for February 1995 FOMC

Event

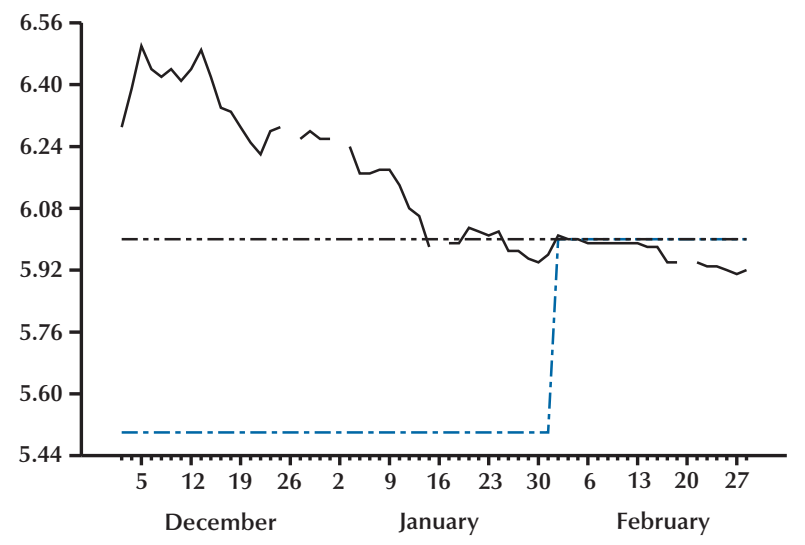

— Feb 1995

- - - Target

- - - Feb Average Target

\section{Figure A3-C}

\section{Funds Futures for September 1998 FOMC}

\section{Event}

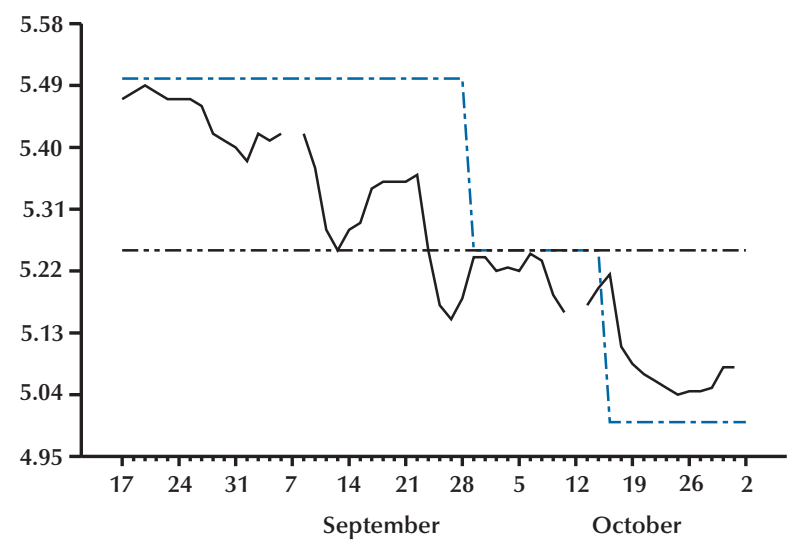

- Oct 1998
- - - Target

-.. Oct Average Target

\section{Figure A3-B}

Funds Futures for March 1997 FOMC Event

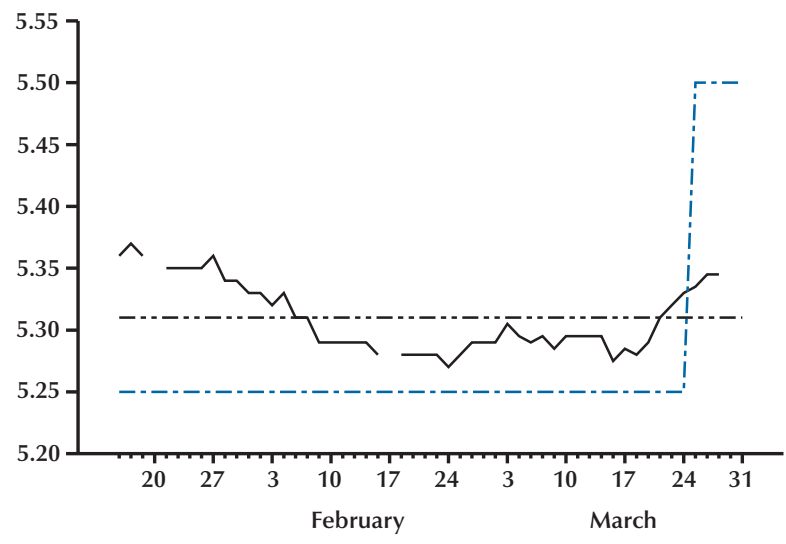

— Mar 1997

- - - Target

-... Mar Average Target

\section{Figure A3-D}

Funds Futures for February 2000 FOMC Event

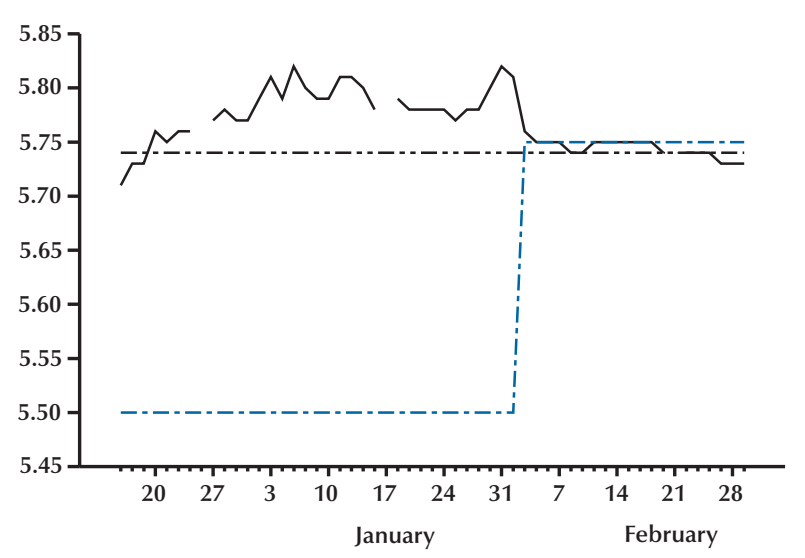

- Feb 2000

-- - Target 


\section{Figure A3-E}

Funds Futures for May 2000 FOMC Event

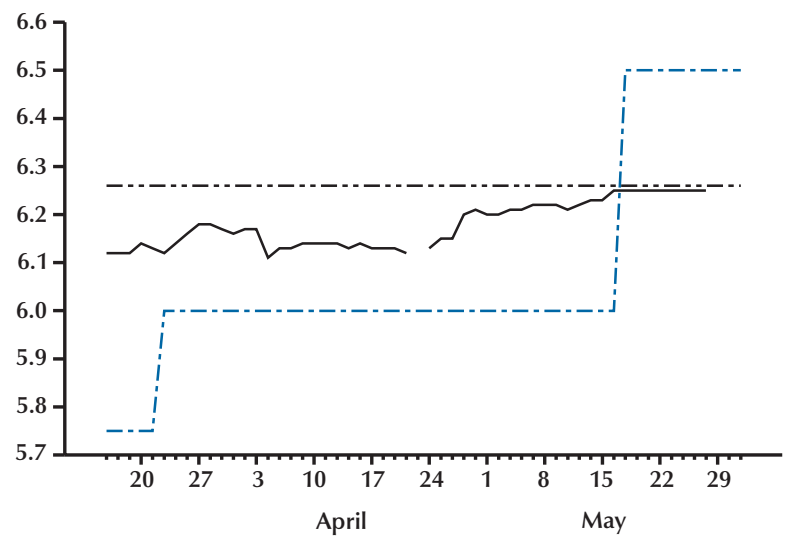

— May 2000

-- - Target

-... May Average Target

\section{Figure A3-F}

Funds Futures for January 2001 FOMC Event

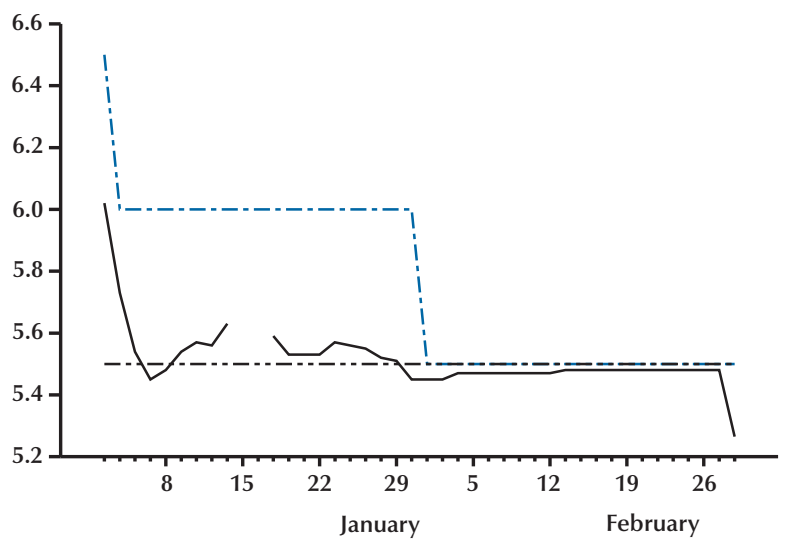

- Feb 2001

\section{Figure A3-G}

\section{Funds Futures for May 2001 FOMC Event}

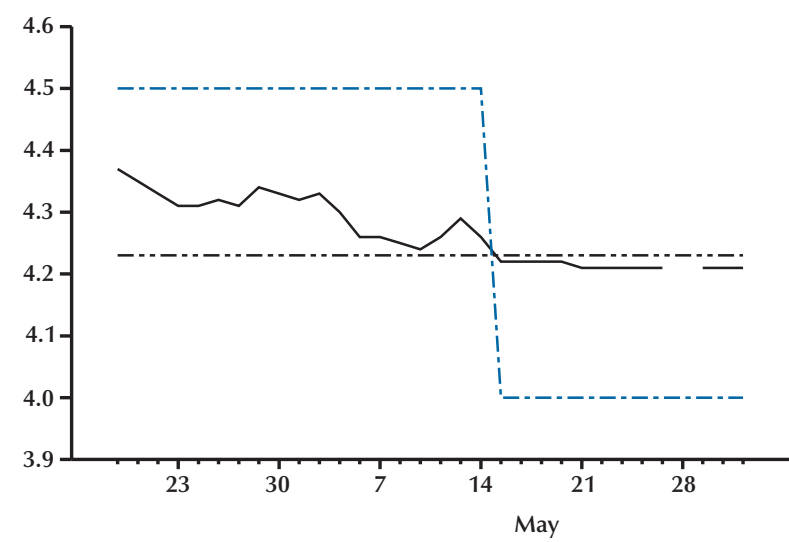

— May 2001

- - - Target

-.- May Average Target 


\section{Figure A4-A}

Funds Futures for December 1988 FOMC Event

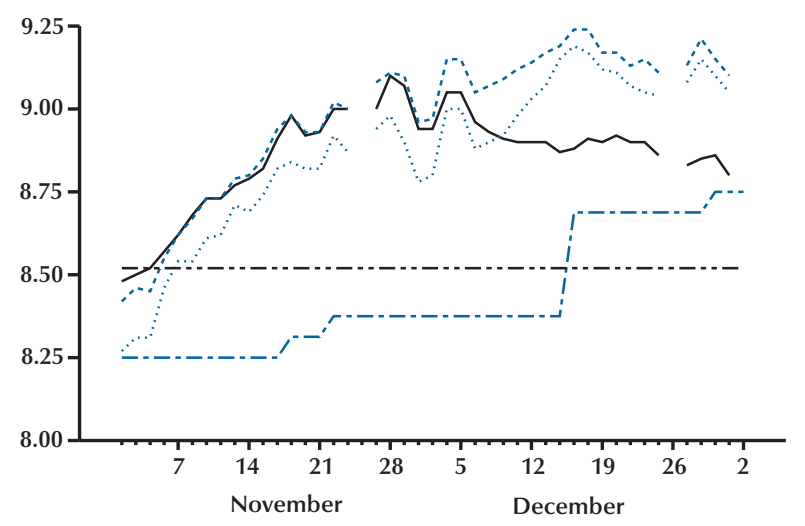

- Dec 1988

- . - - Jan 1989

-... Dec Average Target

\section{Figure A4-B}

Funds Futures for February 1989 FOMC Event

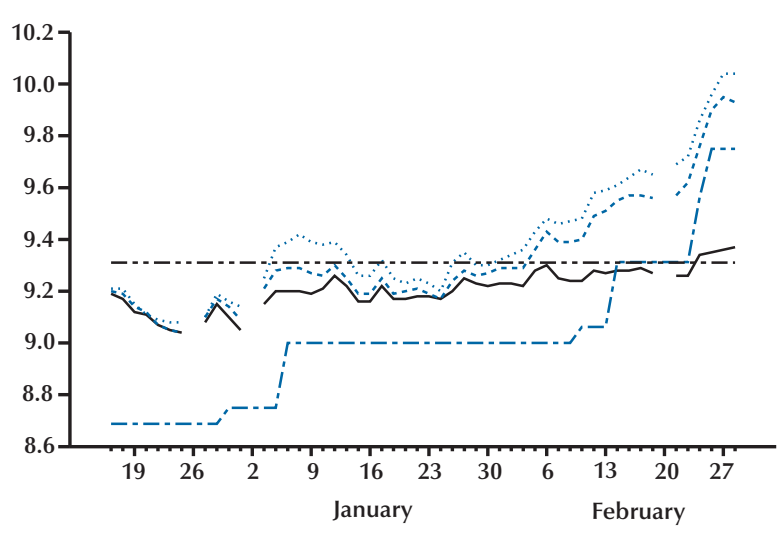

— Feb $1989 \quad$ - - . . M Mar 1989

Apr 1989

- - - Target

\section{Figure A4-C}

\section{Funds Futures for June 1989 FOMC Event}

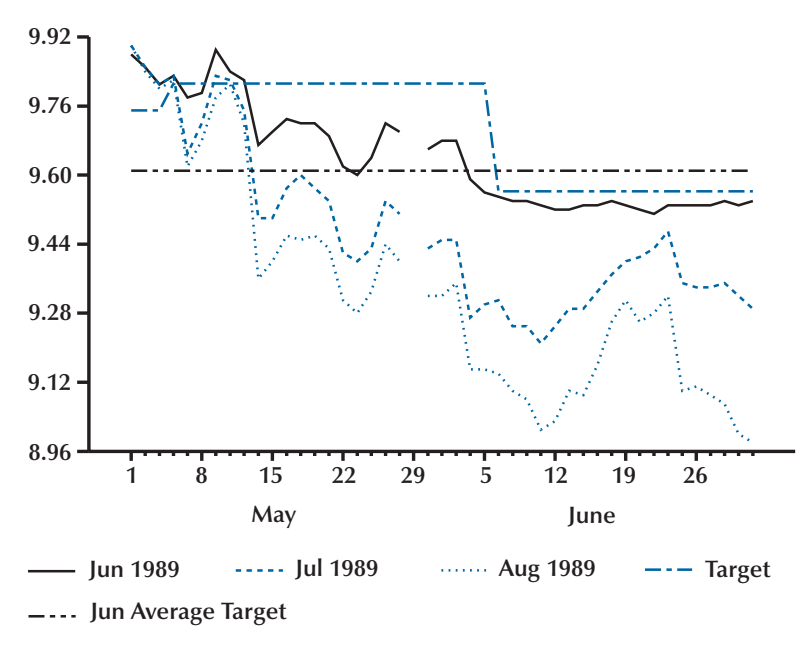




\section{Figure A4-D}

Funds Futures for October 1990 FOMC Event

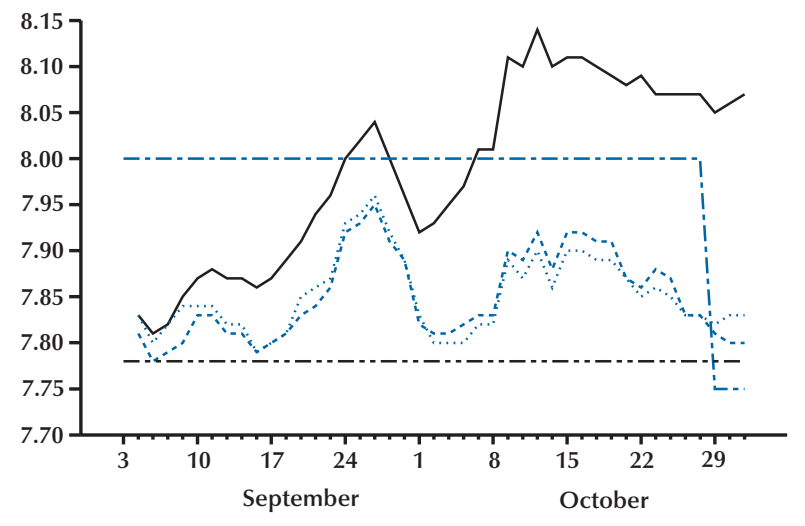

— Oct $1990 \quad$ - - - . Nov 1990

Dec 1990

-- Target

\section{Figure A4-E}

Funds Futures for September 1991 FOMC Event

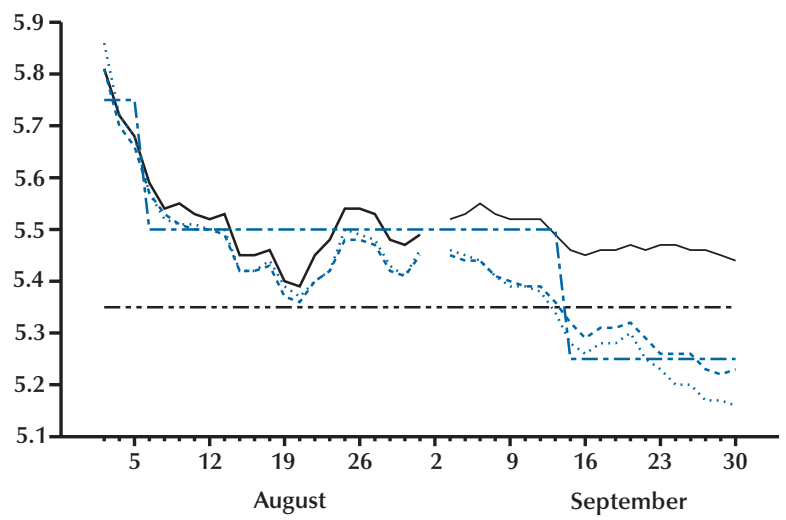

— Sep $1991 \quad$-.... Oct $1991 \quad$....... Nov $1991 \quad$ - - - Target

-... Sep Average Target 
